\title{
Wildlife Economics The Significance of Economic Impacts of Wildlife Associated Activities
}

\author{
Caleb Anthony Stair
}

Follow this and additional works at: https://researchrepository.wvu.edu/etd

\section{Recommended Citation}

Stair, Caleb Anthony, "Wildlife Economics The Significance of Economic Impacts of Wildlife Associated Activities" (2018). Graduate Theses, Dissertations, and Problem Reports. 7260.

https://researchrepository.wvu.edu/etd/7260

This Dissertation is protected by copyright and/or related rights. It has been brought to you by the The Research Repository @ WVU with permission from the rights-holder(s). You are free to use this Dissertation in any way that is permitted by the copyright and related rights legislation that applies to your use. For other uses you must obtain permission from the rights-holder(s) directly, unless additional rights are indicated by a Creative Commons license in the record and/ or on the work itself. This Dissertation has been accepted for inclusion in WVU Graduate Theses, Dissertations, and Problem Reports collection by an authorized administrator of The Research Repository @ WVU.

For more information, please contact researchrepository@mail.wvu.edu. 


\title{
Wildlife Economics
}

\section{The Significance of Economic Impacts of Wildlife Associated Activities \\ Caleb Anthony Stair}

Dissertation submitted to the Davis College of Agriculture, Natural Resources, and Design at West Virginia University

in partial fulfillment of the requirements for the degree of Doctor of Philosophy in the Division of Resource Economics and Management

\author{
Randall Jackson, Ph.D., Chair \\ Peter V. Schaeffer, Ph.D. \\ Donald Lacombe, Ph.D. \\ Heather Stephens, Ph.D. \\ Christa Court, Ph.D. \\ Department of Resource Economics and Management
}

Morgantown, West Virginia

2018

Keywords: Economics, Wildlife, Spatial Econometrics, Regional Economics, Tourism Copyright 2018 Caleb Anthony Stair 


\section{ABSTRACT \\ Wildlife Economics: The Significance of Economic Impacts of Wildlife Associated Activities}

\section{Caleb Anthony Stair}

Like baseball and apple pie, wildlife is an integral part of life in the United States. Wildlife interactions and conservation are traditions shared by many Americans. Recently there has been a greater demand for more complex skills needed to address human-wildlife conflict, aspects of wildlife management, and conservation. The wildlife professional of today needs more than what a basic degree in wildlife science, management, or conservation provides. This poses a particular challenge because wildlife impacts not only people living in areas containing wildlife, but also people located in neighboring areas. Therefore, costs and benefits for wildlife "source" areas will differ from those faced by other areas. One particular issue with wildlife related research is that all too often many of the costs of wildlife are not fully considered. Some economists are now trying to quantify the informal nature of the wildlife sector. This new field has little formal organization and its researchers are scattered among many academic fields. This dissertation deals with emerging wildlife issues and discusses how wildlife professionals can address these problems. The following combination of three related essays exhibits the usefulness of spatial econometrics when measuring the impacts of human-wildlife interactions. These essays deal with prominent wildlife related issues in North America that wildlife professionals will have to address in the near future. These topics include deer-related auto accidents, property damage caused by black bears, and the impact of shark attacks on hotel occupancy. 


\section{Acknowledgments}

It has been a period of intense learning for me, not only with regard to economics, but also on a personal level. Over the past four years, this dissertation has encompassed my entire educational experience. I am grateful to all of those with whom I have had the pleasure to work with during this and other related projects. I would like to reflect on the people who have supported and helped me so much throughout this time.

Each of my committee members has provided me with extensive personal and professional guidance. They have taught me about not only research but also life in general. Your valuable guidance has definitely provided me with the tools that I needed to choose the right direction and successfully complete my dissertation. Foremost, I would like to express my sincere gratitude to my adviser, Dr. Randall Jackson, for his continuous support of my Ph.D. study and research, for his patience, motivation, enthusiasm, and immense knowledge. His guidance helped me during my research and writing of this dissertation. I could not have imagined having a better adviser and mentor for my Ph.D. studies and life.

Dr. Peter Schaeffer gave me the opportunity to teach with him and learn about higher education. I truly believe we made each other better teachers and that the lessons I learned from him will stay with me throughout my academic life. He has always been supportive of my research and has helped me through the rough parts of my early dissertation.

Dr. Donald Lacombe always explained spatial econometrics in a way that made it seem approachable and useful. His suggestion that I pursue wildlife topics using spatial econometric techniques was the catalyst that started me down this path, and I hope we get to work together in the future.

Dr. Heather Stevens was always willing to take time to go over my research and make insightful suggestions. She even contacted everyone she knew to help me acquire some of the bear data. Her assistance and guidance were crucial to the development and completion of my dissertation.

Dr. Jackson always told me I had big shoes to fill and those belonged to Dr. Christa Court. She is always willing to talk on the phone about Ph.D. life and offered many lessons concerning research. She is a source of inspiration and has not been afraid to tell me everything 
would work out. I want to thank her for all of her guidance and support, and I look forward to learning more from her at the University of Florida.

I would also like to thank my family for their wise counsel and sympathetic ears. You are always there for me. My four younger brothers helped me find data, craft theories, and even taught me Matlab. My father and mother even proofread some of my papers, and I always consulted dad about any theory that I was working on at the time. My father got his Ph.D. from WVU and was a GRA at the Regional Research Institute. I have always wanted to be like my dad. Now, I finally can say that I am Dr. Stair version 2.0.

I would like to thank my colleagues at the Regional Research Institute for their wonderful collaboration and all of the fun we have had over the last five years. You supported me and were always willing to lend a helping hand. We were not only able to support each other by deliberating over our problems and findings, but also happily by talking about things other than just our research. Doris and Caigan treated me as if I was part of their family and were always concerned about my well-being both at RRI and in life in general.

I would particularly like to single out my office-mate and friend Elham Erfanian. Elham, I want to thank you for your excellent cooperation and being a helpful guide throughout the last five years. From helping with code to listening to me, complain about life, I could not have hoped for a better friend. I sincerely have loved the time we have spent together and hope we work together for the rest of our lives. Finally, I would like to thank God for being a source of guidance and strength. I do believe that He put all of these wonderful people in my life and afforded me the opportunity to get my Ph.D. 


\section{Contents}

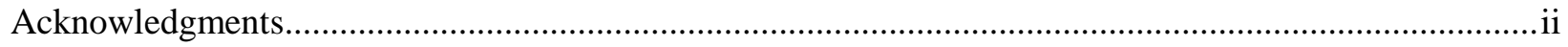

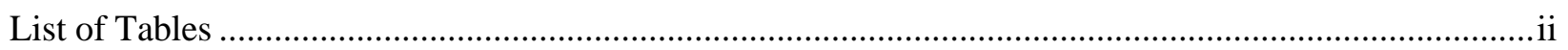

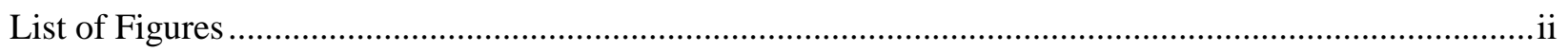

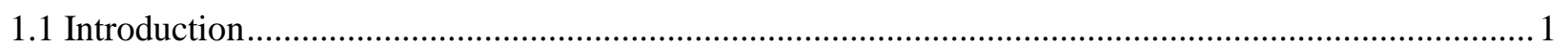

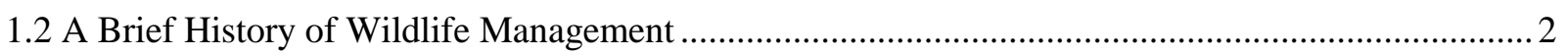

1.3 The Next 50 years of Wildlife Management.............................................................................. 3

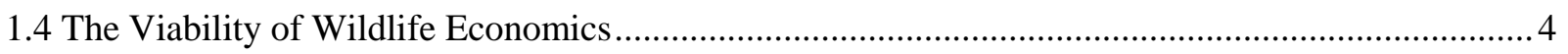

2.1 Deer-Related Auto Accidents: The Hunting Technique Effect: Introduction...................................... 6

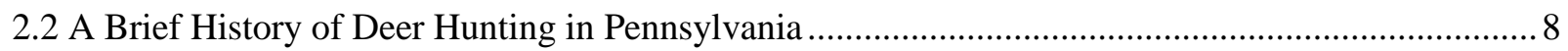

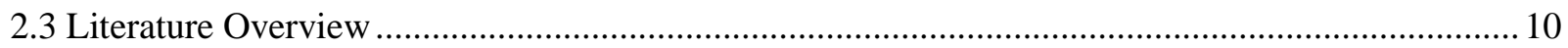

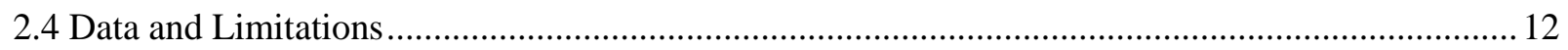

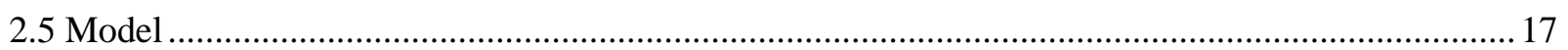

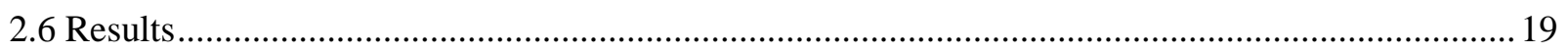

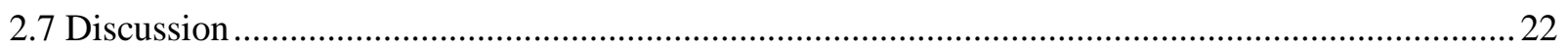

3.1 Bear Hunting and the Spillovers of Bear Property Damages in West Virginia: Introduction ..............23

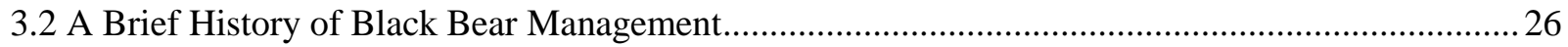

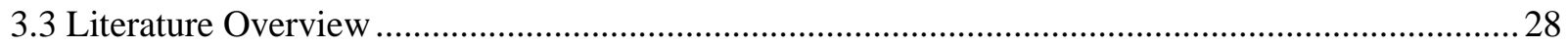

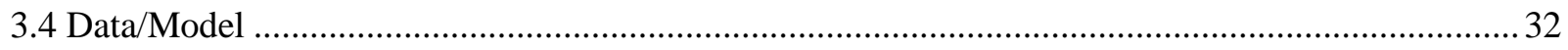

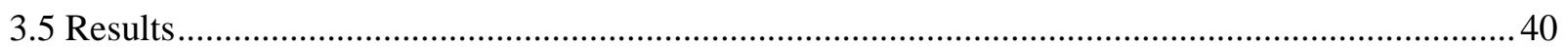

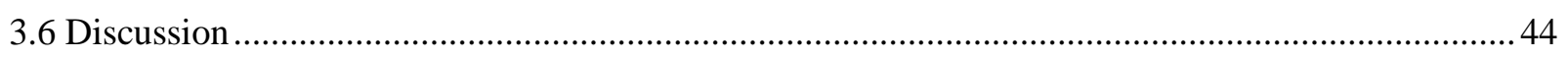

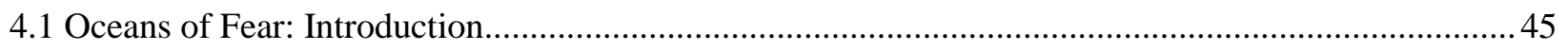

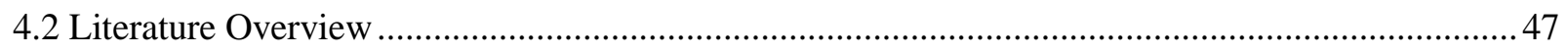

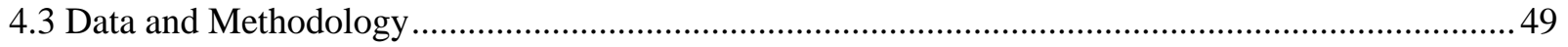

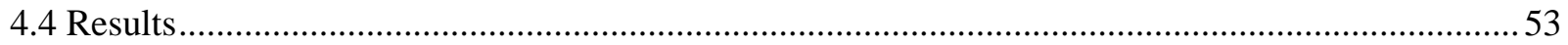

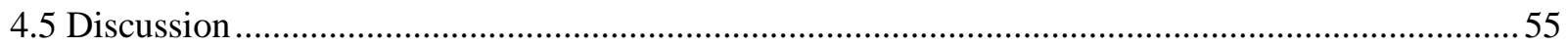

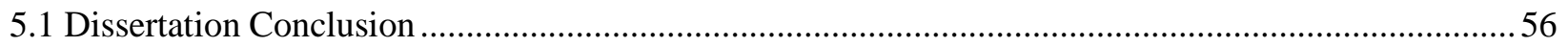

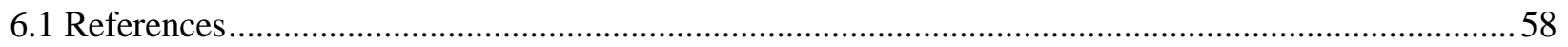

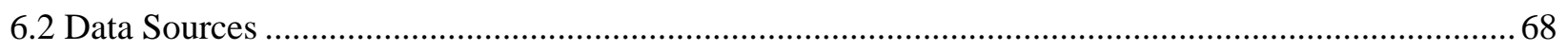

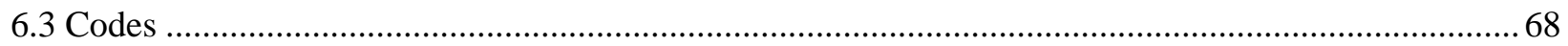




\section{List of Tables}

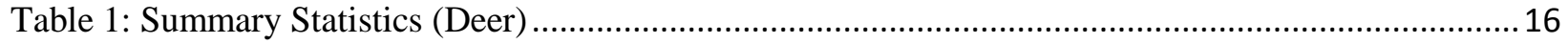

Table 2: Spatial Durbin Model (SDM) Explaining Deer Vehicle Accidents (DRA) from 2009 to 2013 ... 19

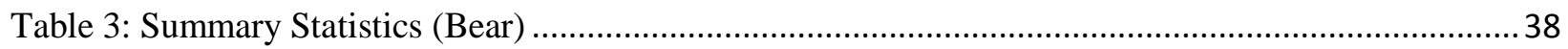

Table 4: Spatial Panel SDEM Results Filled Bear Damage Claims (2005 - 2013) ................................. 40

Table 5: Spatial Panel SDEM Results Nuisance Phone Calls (2005 - 2013).......................................... 43

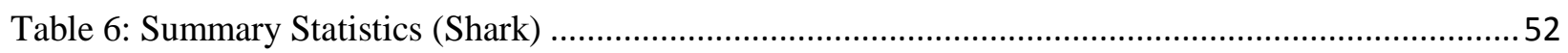

Table 7: Results SDEM Hotel Occupancy in Coastal Carolina Counties (2005 - 2015)..........................53

\section{List of Figures}

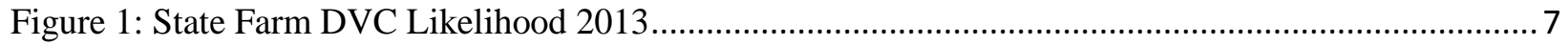

Figure 2: Pennsylvania's Wildlife Management Units......................................................................... 15

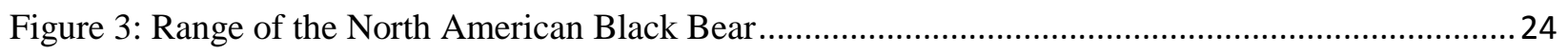

Figure 4: Average Annual West Virginia County-Level Filled Bear Damage Claims (2005 - 2013) ........33

Figure 5: West Virginia Average Annual County Bear Harvest (2005 - 2013) ....................................... 34

Figure 6: West Virginia Counties That Complain About Bears …............................................................ 35

Figure 7: US Shark Attacks by County Since 2000 ….................................................................... 46

Figure 8: Trend of Unprovoked Shark Attacks ............................................................................ 47

Figure 9: Hotel Occupancy in Select Coastal Carolina Counties (2005 - 2016)..................................... 50

Figure 10: Total Hotel Occupancy in All Included Coastal Carolina Counties (2005 - 2016) ................... 50

Figure 11: Shark Attacks in Select Coastal Carolina Counties (2005 - 2016) ........................................ 51

Figure 12: Total Shark Attacks in Included Coastal Carolina Counties $(2005$ - 2016) ............................51 


\subsection{Introduction}

Similar to baseball and apple pie, wildlife is an integral part of life in the United States. Wildlife interactions and conservation are traditions shared by many Americans. They are associated with healthy activities, steeped in tradition, and touch on the most important aspects of our lives. It is also profitable. A survey conducted in 2011 by the U.S Fish and Wildlife Service revealed that over 90 million U.S. residents 16 years of age and older participated in wildlife-related recreation (U.S Fish \& Wildlife Service, 2011). During that year, 33.1 million people fished, 13.7 million hunted, and 71.8 million participated in at least one type of various wildlife-watching activities. These included observing, feeding, or photographing fish and other wildlife in the United States (U.S Fish \& Wildlife Service, 2011). The \$144.7 billion wildlife recreationists' spent in 2011 on their activities, which equated to $1 \%$ of the Gross Domestic Product, reflected their eagerness (U.S Fish \& Wildlife Service, 2011).

Some economists are now trying to quantify the informal nature of a large portion of the wildlife sector (Chardonnet et al., 2002). Wildlife enjoyment and conservation involves various costs and benefits; and to achieve an optimal outcome, several different factors should be addressed (Bulte, Van Kooten, \& Swanson, 2003). This is a particularly difficult challenge because wildlife related events affect not only people living in areas where wildlife is located, but also people located outside these areas. Therefore, costs and benefits for wildlife "source" areas will differ (possibly greatly) from those faced by other areas. In 2003, Bulte, Van Kooten, \& Swanson indicated that the main issue regarding wildlife is that often many of the costs are not considered. There is a need for new and complex skills to address human-wildlife interactions. Based on these issues, it is safe to say that wildlife managers today need more than what traditional biology, wildlife management, or wildlife conservation courses can provide.

The essays in this dissertation each measure the costs and benefits of human-wildlife interactions in source and surrounding areas. Spatial econometrics can measure the impact of three prominent negative human-wildlife interactions in North America: deer-related auto accidents, bear damage claims, and shark attacks. This allows for the quantifying of spatial spillover effects of various management policies and interactions. 


\subsection{A Brief History of Wildlife Management}

The history of wildlife management begins with the game laws of Europe that regulated the killing of certain species of wild animals. In England, laws based on earlier forest laws; became common (van Dyke, 2008). Under these laws, killing one of the king's deer was nearly equivalent to killing one of his subjects (van Dyke, 2008). A high social status and owning land were often requirements for the right to hunt and kill animals. Fortunately, during the 1300s, the scope of forest jurisdictions was greatly reduced (van Dyke, 2008).

In fact, prior to the twentieth century, few rules or criteria existed concerning hunting in the United States (Pratt, 2018). It seemed as though hunters killed animals at any time they pleased. During this period, many hunters harvested thousands of animals for their meat, hides, furs, and feathers to sell in a developing market for wildlife (Corey, 2006). The early American settlers had no cause for concern, because they had an exorbitantly large amount of wildlife available to them. Their only real purpose for wildlife management was predator control (van Dyke, 2008).

Problems associated with excessive hunting eventually came to the surface and laws appeared that protected animals from these practices, yet more problems still existed. ${ }^{1}$ The rapid expansion of settlements throughout the country was beginning to limit the habitats available for species of wildlife (Corey, 2006). These settlers' destroyed prime wildlife habitat by plowing fields, mining mountains, damming rivers, and building towns (Corey, 2006). Additionally, hunters shot predators like wolves, mountain lions, and foxes on sight because they were potential threats to domesticated animals (van Dyke, 2008). These activities, combined with unregulated hunting that began to cause noticeable damage to wildlife species. The late 1800s saw rapid declines in the numbers of big game animals in the United States (Corey, 2006). Bison, elk, and white-tailed deer began to disappear from areas where they were normally plentiful (Pratt, 2018). Around this time, Theodore Roosevelt (a hunter and outdoorsman) traveled to the American West and anticipated the large herds of American bison (Pratt, 2018). What he saw instead was that unchecked killing had nearly annihilated the bison herds. ${ }^{2}$

\footnotetext{
${ }^{1}$ The earliest record of wildlife management occurred in the Mass. Bay Colony in 1630, paying one penny per wolf killed, aiding in predator control, and in 1779 the Act of the Preservation of Deer passed in Vermont. This act protected bucks, does, and fawns January -June (van Dyke, 2008).

2 At one time, there were so many buffalo that Buffalo Bill Cody would shoot 200 American Bison per day. In one month, he shot 4,280. It is estimated that between 1871-1872, hunters shot 8.5 million bison (Pratt, 2018).
} 
Concern over these wasteful practices led to the creation of laws to protect game animals by regulating hunting (Corey, 2006). In 1901, Roosevelt became president, and his experiences and adventures in the west helped form many of his wildlife policies (Pratt, 2018). After realizing that indecisiveness could result in the extinction of many species, he introduced federal laws regulating hunting and fishing and even established refuges for wildlife (Pratt, 2018). He also established a force of game wardens in each state and they enforced these new laws. In 1909 (over 100 years ago) when Roosevelt left office, he had helped establish 150 national forests, 18 national monuments, 51 national wildlife refuges, and five national parks (Pratt, 2018).

In spite of Roosevelt's efforts, the public's main concern was to bolster hunting rather than increase the wildlife population until about 1905 (Pratt, 2018). Managers tried to supplement dwindling wildlife populations with animals raised in captivity, but this failed (Corey, 2006). After this, biologists discovered that habitats were crucial for wildlife survival (van Dyke, 2008). Efforts then concentrated on reclaiming existing habitats and reintroducing extirpated species (Corey, 2006). These efforts lead to the inception of wildlife management as more than a pass time for activists and politicians.

Aldo Leopold officially established the profession of wildlife management in the United States in the early 1900s (van Dyke, 2008). He and Herbert Stoddard advocated for the use of modern methods and technology and with the goal to revitalize wildlife habitats (van Dyke, 2008). This would lead to abundant "crops" of valued wild animals. Professionals now try to manage with a more comprehensive approach rather than concentrating on a single species with the goal to enhance the entire ecological system.

\subsection{The Next 50 years of Wildlife Management}

Many of today's influential individuals in wildlife management are baby boomers who came into the field as early as the 1960s and are now considering retirement (Hutchins, 2013). This coming retirement storm could drain the nation of much of its knowledge of wildlife management techniques and practices (Unger, 2007). Approximately $80 \%$ of employees in leadership positions in wildlife management could retire in 2015 according to the Association of Fish and Wildlife Agencies (AFWA) (McMullin, 2004). 
Several other trends in Wildlife Conservation are similarly concerning. Of particular concern is the public's lack of knowledge about the natural world. This is a major challenge because implementing necessary wildlife management policies is more difficult and controversial due to uninformed individuals (Hutchins, 2012). Additionally, Manfredo et al. (2017) found that individuals who believe wildlife exists for their benefit had lower levels of trust in their state wildlife agency. There is a developing set of values in which wildlife and humans coexist as part of a connected community. To summarize these traditionalist and "mutualist" values; traditionalists are more likely to support lethal wildlife control while mutualists prefer to see restrictions placed on humans rather than animals.

The earth's human population has continued to expand and will continue to expand over the next few decades. This will push wildlife into increasingly smaller areas of remaining habitat and increase the occurrence of conflicts between humans and wildlife (Hutchins, 2012). Additionally, the nature of these habitats is changing with some areas becoming colder and wetter and some warmer and dryer. These cause persistent changes in vegetation and can alter entire environments (Hutchins, 2013).

Species can now cross natural barriers thanks to global trade, and invasive species present a major challenge to wildlife managers (Hutchins, 2012). The most destructive of these creatures could cause the extinction of native wildlife species. Failing to manage or eradicate the most damaging of these invasive creatures could have grave consequences (Hutchins, 2013). This is in addition to the thousands of species already classified as endangered or threatened. Finally, there is the increased risk of new diseases and the risks that they pose (Hutchins, 2013). These are just a few of the serious challenges that natural resource professionals will have to face. How can future wildlife managers prepare to address these issues and what are the tools and skills they need to meet these increasingly complicated challenges?

\subsection{The Viability of Wildlife Economics}

The multifaceted aspect of modern conservation makes collaboration among various disciplines necessary. Biologists now need to work in teams with economists, sociologists, psychologists, political scientists, and others in order to reach their ultimate goals (Sands et al., 2012). 
In the past few years, wildlife researches have witnessed sizable improvements in their ability to collect data on animal movement through technology, such as Global Positioning Systems (GPS) (Hebblewhite \& Haydon, 2010). The benefits of GPS are obvious and include the ability to collect detailed location data on many animals that are difficult to study. Hebblewhite \& Haydon (2010) found these benefits come with significant issues including collar failures and exceedingly high costs. Average costs for GPS collars for deer or bears, for example, range from $\$ 2,000$ - \$8,000 (Hebblewhite \& Haydon, 2010). ${ }^{3}$ This often results in overall poor study design caused by reduced sample sizes and leads to conclusions that are based on (at best) faulty statistical inferences.

The high cost per GPS unit leads to an unintended influence on sample sizes used in wildlife related studies (Hebblewhite \& Haydon, 2010). Researchers must often use fewer GPS units and instead use more Very High Frequency (VHF) units. These tradeoffs can lead to the unwitting sacrifice of robust population-level inferences (Hebblewhite \& Haydon, 2010). Lindberg \& Walker (2007) discuss the effects of this trade-off between GPS and VHF units in survival studies and find 20 animals or more are needed to make consistent statistical inferences. This number increases to 75 for realistically complex studies (Lindberg \& Walker, 2007). Börger et al. (2006) also argued for a greater number of animals included in these types of studies. Others like Murray (2006) and Leban et al. (2001) argue for increasing the sample size of animals. For example, for studies different kinds of studies about animal survival indicate that 50-100 animals are needed for consistent statistical inferences (Murray, 2006). Considering the cost of 50-100 GPS units this is highly prohibitive. Even studies about resource selection require 30 unit sample sizes for useful analysis (Leban et al., 2001).

These issues do not even address how representativeness of the sample size, which is a function of the total population. 20 individuals sampled out of a population of 200 are far more representative of that population than 20 individuals sampled out of a population of 200,000. Authors can mistake increased precision acquired from a limited number of individuals as representative of the entire population (Hebblewhite \& Haydon, 2010). Therefore wildlife managers should follow the practices of good study and research design and attempt to secure an

\footnotetext{
${ }^{3}$ Depending on the features of the collar, battery size, longevity, program-ability, remote data access via UHF or satellite communication, etc. (Hebblewhite \& Haydon, 2010).
} 
appropriate number of GPS units if population-level conclusions are the goal (Hebblewhite \& Haydon, 2010).

Perhaps it is the case that knowing what an animal does every five minutes is not entirely useful to wildlife managers. At the very least, it may give the erroneous impression that detailed location and time stamped data outweigh representative sample sizes. Too often, it is stated that insights of GPS telemetry will enable wildlife managers to mitigate damages without highlighting its limitations (Hebblewhite \& Haydon, 2010). While there are examples where detailed data are of obvious value, it is not necessarily true in all cases. Therefore, from a data collection standpoint, the most difficult problem facing managers using GPS data is how to scale-up to the total population (Hebblewhite \& Haydon, 2010).

An effective option for modeling the movement of animals is spatial econometrics. It is the field where spatial analysis and econometrics intersect. It could be useful to wildlife managers by modeling the movement of animals by tracing their effects on the area. While this is not a perfect substitute for GPS collars, spatial econometrics is a relatively inexpensive and highly adaptable tool, which can better inform wildlife managers and policy makers about the movement and effects of animal populations. Furthermore, it can be used to measure how humans respond to wildlife. These interactions can be positive (bird and whale watching) or negative (shark attacks and deer-vehicle collisions).

The following three essays demonstrate the usefulness of spatial econometrics when measuring the impacts of human-wildlife interactions. These essays deal with prominent wildlife related issues in North America, including deer-related auto accidents, property damage caused by black bears, and the impact of shark attacks on hotel occupancy.

\subsection{Deer-Related Auto Accidents: The Hunting Technique Effect: Introduction}

A deer-vehicle collision (DVC) is when a deer and a vehicle crash into each other on a roadway. It most often leads to deer fatality, property damage, and human injury (and sometimes death) (State Farm, 2015). The number of accidents, injuries, and fatalities varies by year and region. An estimated 1.23 million deer-related accidents transpired in the United States during a one-year period that ended June 2012 (State Farm, 2015). These accidents resulted in $\$ 3,305$ in 
average property damage (State Farm, 2015). These collisions cause approximately 200 human deaths and $\$ 1.1$ billion in property damage every year (Sudharsan \& Winterstein, 2006). State and federal governments, insurance companies, and drivers spend an additional $\$ 3$ billion in attempts to mitigate the increasing number of deer-vehicle collisions (NHTSA, 2002). There is no consensus in the ongoing debate about what the main contributing factor of a deer-vehicle collision is and many factors are still misunderstood.

The most common type of deer involved in deer-vehicle collisions are white-tailed deer, and they have steadily increased in numbers throughout the United States since the turn of the 20th century when new laws and regulations bolstered their numbers (Hubbard et al., 2000). They are hardy animals and can adapt to a wide range of habitats (Alejandro \& Alfonso, 2010). The State Farm insurance agency has compiled a record of its customer's deer vehicle collisions since 2007, and it has used these data to estimate the likelihood of drivers in different states being involved in this type of accident. Figure one below shows the results of this study for 2012 (State Farm, 2012).

\section{Figure 1: State Farm DVC Likelihood 2013}

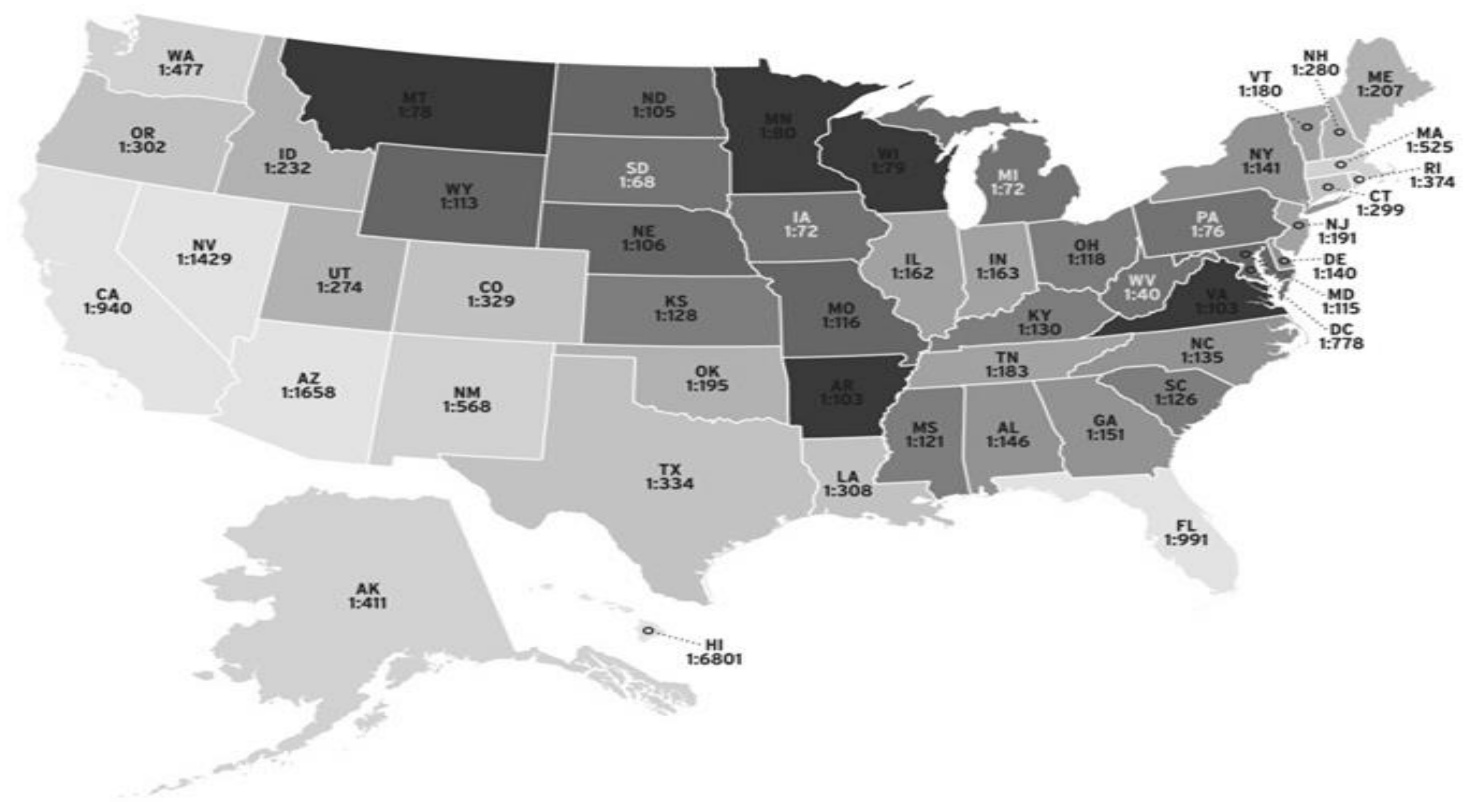

As seen in Figure 1, five northern states (shown in grey) have significantly higher DVC likelihoods. Pennsylvania, Iowa, Michigan, South Dakota, and West Virginia account for 34\% of all DVCs in the US (State Farm, 2012). The total number of DVCs reported in 2012 was 
1,231,710. State Farm insurance indicates that Pennsylvania alone accounted for almost 115,000 collisions in 2012, which amounted to nearly $\$ 400$ million in damages (Schmitz, 2013). That amounts to an average damage claim of over $\$ 3,400$ for that period.

The commonly held belief is that larger deer populations within a state will lead to a greater frequency of deer related accidents in the state (Huijser et al., 2007) ${ }^{4}$. Therefore, a reduction of the deer herd should lead to a decrease in deer-related accidents. Most states use lethal methods for managing deer in the form of regulated hunting (McShea et al., 2008). ${ }^{5}$ While hunting does reduce deer populations, it also alters deer movement patterns (Grau, 1980). Deerrelated accidents conspicuously increase from August through November (Allen and McCullough, 1976). Wildlife biologists attribute this increase to rutting activity because hunting seasons and deer mating seasons (rut) typically coincide (Sudharsan et. al., 2006). This assumption ignores any separate impact deer hunting may have on deer movement, deer mating behavior and car accidents. Deer related auto accidents (DRAs) are the sum of deer-vehicle collisions (when a deer is hit) and sudden-deer accidents (when a car wrecks because of trying to miss a deer) this goal of this analysis is to identify the effect different hunting methods have on deer-related car accidents and rutting activity. The second objective is to determine if regional wildlife management policies have spillover effects.

\subsection{A Brief History of Deer Hunting in Pennsylvania}

Pennsylvanians have hunted the white - tailed deer since the first humans stepped foot on the land. In 1683, hunting was a right of land ownership in the area covered by William Penn's Charter (Schneck, 2014). Pennsylvanian communities relied on deer for food, clothing, and shelter. Extensive hunting and an abundance of natural predators held deer populations to a low estimated density of 8 to 15 deer per square mile (Horsley \& Stout, 2004). When more European settlers entered the region, land clearing and timbering boosted deer populations (Horsley \&

\footnotetext{
${ }^{4}$ Grau (1980), Aaron and Luis Iverson (1999), Bissonette et al. (2008), and Schwabe et al. (2000), echoes this sentiment that more deer leads to more accidents.

${ }^{5}$ The explosion of deer across the eastern U.S. has prompted some cities and towns to cull them. Ann Arbor, Michigan, used a combined sharpshooting cull and sterilization of does. Mount Lebanon, Pennsylvania, has tried archery and sharpshooting culls (Hurley, 2017).
} 
Stout, 2004). ${ }^{6}$ The elimination of native predators by hunting and trapping exacerbated this effect.

As timber harvesting in the region accelerated, venison was the meat of choice for logging camps, growing settlements, and urban markets (Horsley \& Stout, 2004). Hides were also highly valued and people hunted deer year-round to provide food and clothes for these new industries and settlements (Horsley \& Stout, 2004). Around the late 1800s, deer almost cease to exist in the entire state of Pennsylvania (Horsley \& Stout, 2004). When users withdraw resources to secure short-term gains and ignore the long-term consequences, the term "tragedy of the commons" is used. The Pennsylvania Game Commission (PGC), established in 1895, attempted to address the public's reaction to this tragedy of the commons issue (Schneck, 2014).

The PGC decided to limit the harvest of deer by imposing hunting seasons and even outlawed the harvest of does during this time (Schneck, 2014). ${ }^{7}$ They also reintroduced 700 whitetails from other states (Horsley \& Stout, 2004). These protections and re-introductions coincided with substantial timber harvesting that produced almost ideal habitat for white-tails across the state, and deer numbers doubled every two years from 1907 to 1923 (Horsley \& Stout, 2004).

Deer populations grew so much that they started to become a nuisance. By 1923, farmers were urging for doe seasons to reduce damage to crops, and by the end of the decade, foresters were making similar pleas (Horsley \& Stout, 2004). Despite the establishment of doe season, the effects of overpopulation of deer began to appear in northwestern Pennsylvania forests. In the wake of mounting deer losses to starvation in winter due to deer populations out of sync with their habitat, the PGC in1928 decided to suspend the buck season for the first time in state history and replace it with a doe season in 51 of the state's 67 counties (Schneck, 2014). However, the resulting reduction in the deer population was so extreme that it became a major headline if anyone even saw a deer track (Horsley \& Stout, 2004).

\footnotetext{
${ }^{6}$ Deforestation can benefit deer in reality. The white-tailed deer is a species that flourishes in habitats along the edges of forests and roadways. This is why they have been so successful in the suburbs. See Horsley, Stout, \& DeCalesta (2003)

${ }^{7}$ The first official hunting season (Sept. 1-Dec. 31) was in 1869 and was run by the state government rather than the PGC (Schneck, 2014).
} 
The deer population began to recover in the 1940s when many of the hunting population were fighting during WWII. Pennsylvania's first archery deer season occurred in 1951, the same year that the PGC began issuing antlerless deer licenses by county (Schneck, 2014). Winter archery season appears in some parts of the state in 1964 and made statewide in 1967. Compound bows, which employ a series of pulleys and mechanics, first appeared in 1973 (Schneck, 2014).

Although the late 1990s saw encouraging new initiatives that would allow hunters to reduce deer populations and their impacts across Pennsylvania, many areas have developed serious problems after more than 70 years of deer overabundance (Horsley \& Stout, 2004). It is difficult to deny that Pennsylvania can produce some impressive deer harvests. In 2013, Pennsylvania hunters harvested 127,540 bucks, along with 208,660 antlerless deer (Hayes, 2017). This combined with the moderate weather makes Pennsylvania very popular for hunters. ${ }^{8}$ It ranks highest in hunter density and large yearling buck harvest (Hayes, 2017).

\subsection{Literature Overview}

In general, the literature indicates that three components must exist for a DVC to occur: a road, car, and deer have to exist at the same time in the same space. Therefore, the general strategies to reduce DVCs are to modify roadways, modify deer behavior, or reduce the number of deer. The timing of the rut is the most commonly cited reason for the increase in DVCs during the fall (see Allen and McCullough, 1976, Sudharsan et al., 2006, and Grau, 1980). However, McShea et al. (2008) analyzed vehicular collisions with white-tailed in Clarke County, Virginia, from August through December 2005 and 2006 and noted the locations of DVCs during the rut were not obviously different from collisions outside the rut (McShea et al., 2008). The characteristics of the road and the amount of housing development nearby were important attributes when predicting DVCs. ${ }^{9}$ They advocated changing motorist behavior and the characteristics of roads.

Aaron and Luis Iverson (1999) studied the temporal and spatial trends of DVCs and deer harvest in Ohio from 1988-1995. They found no apparent relationship between deer-harvest and

\footnotetext{
${ }^{8}$ The white-tailed deer was selected as Pennsylvania's state animal in 1959 (Schneck, 2014).

${ }^{9}$ Data concerning road characteristics in Pennsylvania are rather sparse. This is partially because the Pennsylvania Department of Transportation constantly has roads under construction.
} 
DVCs (Aaron and Luis Iverson, 1999). The authors indicated that major factors are the amount of urban land in the county and the number of highway miles in the county. In related research looking at motor vehicle collisions using remotely sensed landscape data, a Swedish group of researchers found traffic volume, vehicle speed, and fences were the dominate factors in determining moose-vehicle collisions. Moose density measured by harvest statistics and distance to forest cover were also significant (Seiler, 2005). However, noting the widespread consensus that speed is correlated with deer-vehicle collisions, Bissonette et al. (2008) examine the relationship between annual average daily traffic, posted speed limit, and deer-vehicle collisions, finding no relationship. The authors suggest that while these may be useful explanatory variables, average traffic and posted speed limit, may be poor surrogate variables for actual road conditions so that the resulting risk predictions will be unreliable (Bissonette et al., 2008).

Deer population density and location may seem like important factors influencing the likelihood of deer vehicle collisions, but detailed data are typically not available so proxy variables tend to appear in research studies. For example, Schwabe et al. (2000) used the county buck gun harvest per square mile and the doe gun harvest per square mile. They find statistical significance for bucks, more bucks more collisions, but not for does. In a later, similar study, however, several of the same authors (Schwabe, Schuman, \& Tonkovich) report a positive relation between deer-vehicle collisions and the number of bucks harvested per square mile in the county but a negative relation for the number of does harvested, both significant at better than the one percent level (Schwabe et al., 2002). The logical policy implication of this research would be to reduce the number of does harvested in order to reduce collisions. Several states actively increase doe harvest to reduce deer populations in order to reduce collisions because this policy recommendation would be likely to generate some skepticism. In addition, a Pennsylvania study found that male and female deer mortality from deer-vehicle collisions was generally similar (Puglisi et al., 1974).

With regards to DVCs, hunting is both a contributing and mitigating factor. Several studies have focused on the effectiveness of reducing the deer herd at limiting DVCs. DeNicola and Williams (2008) advocated a method of culling deer populations to lower DVCs. The authors conducted sharpshooting culls in three suburban areas to reduce deer numbers and 
measure the related impact on DVCs. ${ }^{10}$ Deer populations were reduced by $54 \%, 72 \%$, and $76 \%$, and resulted in decreases in DVCs of 49\%, 75\%, and 78\%, respectively (DeNicola and Williams, 2008). Novak et al. (1991) used a stochastic, catch-effort, competing risks model to estimate the population size of the Savannah River Site white-tailed deer herd for 1965-86. The total population varied distinctly in response to changes in hunting techniques and the amount of hunting pressure. They found that hunters who remained stationary preferred to harvest more mature animals compared to dog hunters (Novak et al., 1991). However, dog hunters were 2.37 times more likely to harvest a deer compared to still-hunters (Novak et al., 1991).

While the overall impact that hunting has on DVCs has been discussed, there is a conspicuous lack of literature concerning the impact that different hunting implements have on DVCs. Hunting is traditionally grouped together as one variable or separated out by gender of the deer (buck vs doe harvest). However, this ignores the hunters themselves. This paper investigates what role technique plays in DRAs and finds that hunting technique does affect DRAs.

\subsection{Data and Limitations}

This study uses a panel data set of the 67 Pennsylvania counties for the period 2009 to 2013. ${ }^{11}$ Pennsylvania is the study region because it has the highest number of deer-related auto accidents in the U.S. and its hunting data are more readily available as compared to other states (Schmitz, 2013). ${ }^{12}$

The Pennsylvania Department of Transportation (PennDot) provides DRA data. This is different from DVCs because deer-related auto accidents include collisions as well as accidents where a driver was involved in an accident while attempting to avoid a deer. PennDot records accidents that require PennDot employees to respond, which are usually more severe. As far as auto insurance companies are concerned, hitting a deer is typically a covered loss.

Comprehensive coverage typically provides this protection. Since this is a not an at "fault" type

\footnotetext{
${ }^{10}$ The authors implemented sharpshooting management projects in lowa City, lowa; Princeton, New Jersey; and Solon, Ohio.

${ }^{11}$ Unfortunately, monthly hunting and crash data are not readily available. Previous studies obtained monthly crash data through police reports. This was not possible given the time frame of this study.

${ }^{12}$ State Farm reported 126,275 collisions in the state from July 1, 2014 to June 30, 2015. Schmitz indicated that in 2013 deervehicle collisions caused approximately $\$ 400$ million in damages.
} 
of loss, an insurer is likely to process this through your comprehensive insurance coverage (Allstate, 2011). The random and unpredictable event of a deer sprinting and bounding across a highway or rural road is certainly different from other types of automotive accidents. Deer related accidents usually fall under comprehensive coverage, where there is no fault assigned (Huffman, 2015). Therefore, the study assumes that there are no significant reporting issues.

This analysis tests the assumption that an increase in deer movement leads to more deer crossing roads. Deer tend to migrate and mate between October and December, so they are more active and apt to be near roadways beginning in late fall (Huffman, 2015). During rut, male deer (bucks) search for females (doe). This is the primary reason different studies conclude that rutting behavior is the primary factor in DVCs (see Allen and McCullough, 1976, Sudharsan et al., 2006, and Grau, 1980). However, this ignores any impact that hunting may have on deer mating behavior. If there are more doe in a given area, the bucks do not have to move as far to find eligible mates. Therefore, if hunters harvest a large number of female deer there may be fewer eligible mates for bucks the following year. Additionally, since the bulk of the whitetailhunting season and rut coincide, rut may be exacerbating the effect.

Additionally, different hunting techniques affect deer in different ways (Grau and Grau, 1980). The appeal of bow hunting is the sportsmanship aspect. Bow hunting requires a great deal of skill, time, practice, and perseverance. Bow hunters enjoy the challenge. Bow hunting also requires a much larger investment of time when stalking and identifying potential targets and, due to the draw weight required and the precision associated with aiming, a much more nimble and skilled hunter. A substantial benefit to bow hunters is that archery season typically is much longer, and starts much earlier in the year than firearm hunting. This allows a bow hunter to hunt before gun hunters. The primary drawback of bow hunting is that not everyone is Robin Hood. It is exceptionally difficult for an archer to land a killing blow. To be successful, an archer must be much closer to the target than with a gun. Therefore, upsides of firearms are obvious. The killing power and long range a rifle provides is plainly superior. A bow hunter would be hard-pressed to kill a deer in excess of 40 yards. A rifle can perform at double the range, and is more likely to deliver a killing blow in one shot. Less experienced hunters will also tend to have more success with a gun. It is much easier to become a good shot with a rifle than it is with a bow. Hunters looking to harvest deer with the smallest amount of time, skill, and effort are primarily going to 
use firearms. In summary, gun hunting and bow hunting both have their challenges and difficulties. Bow hunters tend to be more stationary while other hunters are more active (Novak et. al., 1991). A hunter who is chasing and driving deer forces deer populations to move more compared to bow hunters. However, bow hunters are not as effective at harvesting deer as other hunters armed with guns. Therefore, it is worth investigating the effects of each technique on DRAs.

The Pennsylvania Fish and Game Commission provide Hunting and deer harvest data. Hunting permit data are available at the county level. In the state of Pennsylvania, hunting permits exist in two different categories: resident and non-resident. ${ }^{13}$ Two permit types are included in the analysis. Antlerless permits are a proxy for firearm hunting and archery permits for bow hunting. ${ }^{14}$

The Pennsylvania Game Commission (PGC) separates the state into 23 Wildlife Management Units (WMUs). Currently, the PGC only publishes deer harvest data at the WMU level. WMUs include portions of counties and the description of boundaries is too vague to determine the actual proportion of a county included in the unit. ${ }^{15}$ The map of Pennsylvania Wildlife Management Units is below figure 2. For the purpose of this paper, harvest data are assumed to be uniformly distributed in each WMU. This assumption allows the harvest data to be disaggregated and assigned to a county. ${ }^{16}$ The antlerless deer harvest from the previous year is a measure of how successful hunters are at eliminating the animals that are most likely to strike a vehicle. Allen \& McCullough, (1976) noted that vehicles are more likely to strike young deer and females rather than adult males.

\footnotetext{
${ }^{13}$ Resident permits are issued to residents of Pennsylvania ages 17 through 64. Nonresident permits are issued to nonresidents of Pennsylvania ages 18 or older according to the Pennsylvania Game Commission.

${ }^{14}$ The majority of antlerless permits are purchased and filled during the regular fall firearm hunting season in Pennsylvania. According to the PGC, most are filled after Thanksgiving.

${ }^{15}$ Pennsylvania stopped publishing deer harvest data at the county level in 2004 and county level license sales did not become available until recently.

${ }^{16}$ For example, if Erie County comprises $33 \%$ of WMU 1B, than $33 \%$ of WMU 1B's deer harvest is assigned to Erie County.
} 


\section{Figure 2: Pennsylvania's Wildlife Management Units}

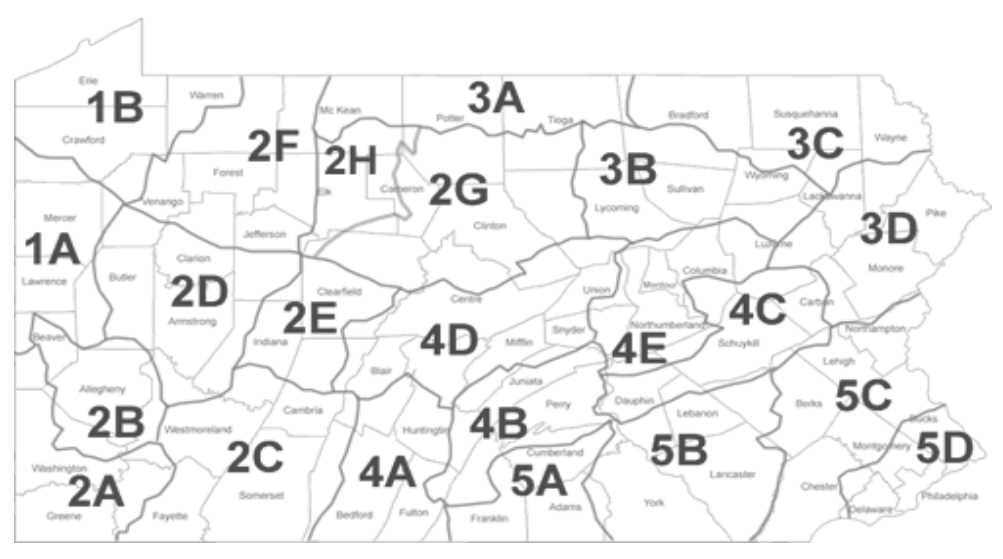

The deer population in a county has been cited previously by the PGC as a major contributor to deer-vehicle collisions; a sentiment echoed by others. ${ }^{17}$ In 2005 , Game Commission (PGC) biologists and researchers from the Cooperative Fish and Wildlife Research Unit (PCFWRU) at Penn State University developed the Pennsylvania sex-age-kill model (PASAK) (Roesenberry et al., 2011). This model releases deer population estimates to the public. While the PASAK model does a serviceable job of observing and categorizing population trends, the models assumptions limit results to relative WMU estimates (Roesenberry et al., 2011). These are disaggregated in a similar way to the antlerless harvest above.

Total daily vehicle miles traveled (DVMT) are included to incorporate a measure of how much a road is used and is the summation for the entire year ${ }^{18}$. This could have one of two effects. First, it could be the case that if drivers more heavily use a road they will be more likely to strike a deer. However, if the road is so popular (non-stop traffic) deer will be more likely to avoid the area.

To account for other states' impact on Pennsylvania's border counties a dummy variable is not practical. Dummy variables will not work here because of the panel setting of the paper. There needs to be variation across years. Therefore, the average number of total deer harvested for each adjacent non-Pennsylvania county is used as a measure of hunting pressure exerted on these border counties. These data exist for Ohio, New York, Maryland, and New Jersey. ${ }^{19}$ They

\footnotetext{
${ }^{17}$ See Schwabe et al. (2000), Schwabe et al. (2002); \& http://www.pgc.pa.gov/Education/WildlifeNotesIndex/Documents/deer.pdf for more details.

${ }^{18}$ Number of registered vehicles per county was previously used but dropped when this became available.
} 
are popular hunting states and the average deer harvest can be almost as high as Pennsylvania's. This is why the border effect measure (shown below in table 1) is large.

Predators play a prominent role in the everyday life of whitetail deer. Coyotes frequently kill young deer (fawns) and will attempt to kill larger deer (Ballard et al., 2001). Recently, black bears became effective predators of deer. In general, bears are opportunistic predators. Although it is clear that black bears prey on deer, their role in deer population dynamics is less certain (Ballard et al., 2001). More commonly, black bears prey upon young deer (fawns). While data concerning coyotes in Pennsylvania are not readily available, the state does manage black bears at the county level. Black bear harvest data are used as a proxy for the black bear population in each county. Summary statistics are shown below in table 1.

Table 1: Summary Statistics (Deer)

\begin{tabular}{|c|c|c|c|c|c|c|}
\hline Variable & Mean & $\begin{array}{c}\text { Standard } \\
\text { Deviation }\end{array}$ & Range & Minimum & Maximum & Count \\
\hline DRAs & 51 & 42 & 278 & 1 & 279 & 335 \\
\hline Doe Harvest t-1 & 3057 & 1851 & 12963 & 37 & 13000 & 335 \\
\hline Antlerless Permits & 12949 & 7572 & 34142 & 44 & 34186 & 335 \\
\hline $\begin{array}{c}\text { Bow Permits } \\
\text { Non-Res Antlerless } \\
\text { Permits }\end{array}$ & 4161 & 3232 & 17717 & 103 & 17820 & 335 \\
\hline $\begin{array}{c}\text { Non-Res Bow Permits } \\
\text { Bear Harvest Data }\end{array}$ & 57 & 321 & 1736 & 0 & 1736 & 335 \\
\hline $\begin{array}{c}\text { Pop Density } \\
\text { Deer Population }\end{array}$ & 469 & 1436 & 11591 & 12 & 11604 & 335 \\
\hline Border Effects & 2122 & 2768 & 10508 & 0 & 10508 & 335 \\
\hline DVMT & 4073769 & 4379068 & 24966855 & 12952 & 24979807 & 335 \\
\hline
\end{tabular}




\subsection{Model}

The dependent variable in this study is deer-related accidents (DRAs) per 100 square miles in Pennsylvania counties. There are 10 independent variables included in the model. A spatial econometric model is used to determine if spillover effects exist. Kalenkoski \& Lacombe (2013) demonstrate a set of related spatial econometric models. They show the following:

$$
\begin{gathered}
y_{i t}=\delta \sum_{j=1}^{N} w_{i j} y_{j t}+x_{i t} \beta+\sum_{j=1}^{N} w_{i j} x_{i j t} \gamma+\mu_{i}+\lambda_{t}+u_{i t} \\
u_{i t}=\rho \sum_{j=1}^{N} w_{i j} u_{i t}+\varepsilon_{i t}
\end{gathered}
$$

In the above model, $y_{i t}$ is an observation on the dependent variable at $i$ and $t, x_{i t}$ is a (1, $\mathrm{K})$ row vector of observations on the explanatory variables, and $\beta$ is a corresponding $(\mathrm{K}, 1)$ vector of fixed but unknown parameters. $i$ represents an index for the cross-sectional dimension (spatial units, or in this case counties in Pennsylvania), with $i=1, \ldots, \mathrm{N}$. The index for the time dimension is shown as $t$, with $t=1, \ldots, \mathrm{T}$. Space and time-period fixed effects are represented by the terms $\mu_{i}$ and $\lambda_{t}$. Finally, to capture the degree of spatial auto correlation, $\delta$ and $\rho$ are included. The addition of extra terms makes the model shown above a spatial panel model (Kalenkoski \& Lacombe, 2013).

The spatial organizations of the components in the sample are an important feature of any spatial econometric model. This organization is shown by a spatial weights matrix, W, "which expresses for each observation (row) those locations (columns) that belong to its neighborhood set as nonzero elements" (Anselin and Bera, p. 243). Individual elements in this spatial weight matrix $w_{i j}$ are equal to 1 if observations $i$ and $j$ are 'neighbors' and 0 if they are not 'neighbors' (Kalenkoski \& Lacombe, 2013). The Wy term is a weighted average of the surrounding observations of the dependent variable and $W u$ is a weighted average of the surrounding error terms. The weight matrix used in this study is a 4-nearest neighbor matrix based on county centroids. $^{20}$ This is a useful specification for the initial investigation. Vinton (2010) indicated

\footnotetext{
${ }^{20}$ The weight matrix used in this research was a K-by-N nearest neighbor's weight matrix. Using maximum likelihood estimation it was determined that the 4-nearest neighbors based on county centroids should be included in the study. Additionally, according to LeSage \& Pace (2014), there is little evidence for the belief that estimates and inferences from spatial regression
} 
that there is an embarrassingly large number of ways to construct a weight matrix. It all depends on context. Drukker et al. (2013) highlighted an inverse distance weight matrix that could be useful when this research progresses.

Kalenkoski and Lacombe (2013) show how special cases are obtained by restricting parameters. If both $\rho=0$ and $\gamma=0$, the result is a spatial autoregressive (SAR) that exhibits spatial dependence for only the dependent variable. If spatial auto correlation is suspected the SAR is appropriate (Kalenkoski \& Lacombe, 2013). Constraining $\rho=0$ results in the spatial Durbin model (SDM). This allows for a spatially lagged dependent variable as well as spatially lagged independent variables. To get spatial dependence in the error term along set $\delta=0$ and $\gamma=$ 0 . This is a spatial error model (SEM) and has spatial dependence in the error term alone. Each of these models can include space and time fixed effects. For this paper, the SDM was compared with the Spatial Durbin Error Model (SDEM). To determine which model was preferred the statistical significance level of the SDM's $\rho$ was compared to the significance level of the SDEM's $\lambda$. The result was that $\rho$ was more statistically significant than $\lambda^{21}$

According to LeSage and Pace (2009) the SDM is appropriate when there are spatially correlated omitted variables in the model, and these variables correlate with an included explanatory variable in the model. If these two conditions exist, the SDM is the most appropriate mode (LeSage \& Pace, 2009). ${ }^{22}$ This model has spatially correlated omitted variables, such as coyote population and forest cover. These correlate with population density. Therefore, in this case both conditions exist. County and year-fixed effects are also incorporated.

models are sensitive to particular specifications used for the spatial weight structure in these models. As long as estimates and inferences are based on the true partial derivatives for a well-specified spatial regression model.

${ }^{21}$ This may seem odd because this paper seems to be geared for local effects. A more thorough model specification will be conducted in the future. 


\subsection{Results}

Table 2: Spatial Durbin Model (SDM) Explaining Deer Vehicle Accidents (DRA) from 2009 to 2013

\begin{tabular}{|c|c|c|c|}
\hline Variable & Direct & Indirect & Total \\
\hline AntlerlessPermits100s & $\begin{array}{c}-0.029 * * * \\
(-3.63)\end{array}$ & $\begin{array}{l}0.007 \\
(0.33)\end{array}$ & $\begin{array}{l}-0.022 \\
(-0.95)\end{array}$ \\
\hline Bear Harvest Data & $\begin{array}{l}-0.007 \\
(-1.67)\end{array}$ & $\begin{array}{l}0.017^{*} \\
(1.72)\end{array}$ & $\begin{array}{l}0.010 \\
(0.90)\end{array}$ \\
\hline BowPermits100s & $\begin{array}{c}0.129^{* *} \\
(2.20)\end{array}$ & $\begin{array}{l}-0.161 \\
(-1.14)\end{array}$ & $\begin{array}{l}-0.032 \\
(-0.21)\end{array}$ \\
\hline AntlerlessHarvestt1100s & $\begin{array}{l}-0.014 \\
(-0.49)\end{array}$ & $\begin{array}{c}-0.138^{*} \\
(-1.84)\end{array}$ & $\begin{array}{c}-0.151^{*} \\
(-1.80)\end{array}$ \\
\hline Pop Density & $\begin{array}{l}-0.002 \\
(-0.30)\end{array}$ & $\begin{array}{c}0.086^{* * * *} \\
(4.60)\end{array}$ & $\begin{array}{c}0.084 * * * \\
(4.06)\end{array}$ \\
\hline DVMT100000s & $\begin{array}{l}0.016 \\
(1.13)\end{array}$ & $\begin{array}{l}-0.052 \\
(-1.28)\end{array}$ & $\begin{array}{l}-0.036 \\
(-0.79)\end{array}$ \\
\hline BorderEffects100s & $\begin{array}{l}0.013 \\
(0.27) \\
\end{array}$ & $\begin{array}{c}0.326^{* *} \\
(2.60) \\
\end{array}$ & $\begin{array}{c}0.339 * * \\
(2.30) \\
\end{array}$ \\
\hline DeerPopulation100s & $\begin{array}{c}0.010^{* *} \\
(2.87)\end{array}$ & $\begin{array}{l}0.007 \\
(0.97)\end{array}$ & $\begin{array}{c}0.017^{* * *} \\
(2.24)\end{array}$ \\
\hline NonRes Bow Permits & $\begin{array}{l}0.002 \\
(0.83)\end{array}$ & $\begin{array}{l}0.003 \\
(0.48)\end{array}$ & $\begin{array}{l}0.005 \\
(0.71)\end{array}$ \\
\hline NonRes Antlerless Permits & $\begin{array}{c}0.00553 \\
(0.56)\end{array}$ & $\begin{array}{l}0.045^{*} \\
(1.80)\end{array}$ & $\begin{array}{l}0.051^{*} \\
(1.74)\end{array}$ \\
\hline \multicolumn{4}{|c|}{$\begin{array}{c}p=0.20394 \\
(t-\text { stat }=2.912, p \text { value }=0.003584)\end{array}$} \\
\hline \multicolumn{4}{|c|}{$\begin{array}{c}R^{2}=0.9488 \\
\operatorname{Corr}^{2}=0.2125\end{array}$} \\
\hline \multicolumn{4}{|c|}{$\begin{array}{l}\text { T-stats are in parentheses below the coefficients. Significance levels are represented by } *=90 \% \text {, } \\
* *=95 \%, * * *=99 \% \text { with } N=335, R^{\wedge} 2=0.9488 \text { and } R^{\wedge} 2 \text { adj }=0.9472 \text {. }\end{array}$} \\
\hline
\end{tabular}

Table 2 presents a pooled SDM model with spatially lagged dependent variable, spatial and time period fixed effects. LeSage and Pace (2009) note that the SDM is the only model that produces unbiased coefficient estimates for all of the data generating processes. Additionally, Elhorst (2010b) indicates that the SDM is more flexible because the signs of the effects estimates are not constrained to be the same. In other words, if the direct effect is positive, then the indirect and total effects will also be positive. In the SDM model, the effects estimates are contingent upon the value of the $\beta$ s. 
Two different measures exist to determine the overall model fit. The first is the R2, which in this model is equal to 0.9488 due to the fixed effects absorbing most of the variation. Elhorst (2010a) highlights an alternative goodness-of-fit measure based on the squared correlation coefficient between actual and fitted values to account for the nature of fixed effects. In this model, that measure is 0.2125 . The difference between the two measures shows how much of the variation in the dependent variable is explained by the fixed effects (Elhorst, 2010a). Results indicate the fixed effects portion of the model explains approximately $74 \%$ of the variation in the dependent variable.

The direct effects indicate how a change in an explanatory variable in the county affects the dependent variable in that county. There are four statistically significant direct effects resulting from Antlerless Permits, Bow Permits, and the Deer Population. Antlerless permits are included as a measure of rifle hunting in a county. Its coefficient of -0.029 indicates that for every additional 100 antlerless license sold there is a decrease of -0.029 DRAs per 100 square miles. In other words, a 668 square mile county (Pennsylvania's average) that sold 100 additional antlerless permits would decrease its DRAs by 0.1932 . This is because they are targeting deer that have an increased risk of striking a car with an effective hunting implement (primarily a rifle).

The direct coefficient for bow permits is positive and significant indicating that every additional 100 bow permits sold is associated with a 0.129 increase in DRAs per 100 square miles. This result seems to indicate that bow hunters are not effective at eliminating deer and perhaps cause more movement by entering the woods and scaring more deer than they kill.

Unsurprisingly, the results indicate that an additional 100 deer in a county are associated with a 0.01 increase in DRAs per 100 square miles. When there are more deer in a county, they have to search more extensively for food and are more likely to cross roads in their search.

The indirect effects measure how a change in an explanatory variable in a county affects the dependent variable in neighboring counties. The four statistically significant indirect effects are bear harvest; doe harvest the previous year, population density, border effects, and nonresident antlerless permits. Bear harvest was included as a proxy for the number of bears in a county. It has a positive indirect effect, which indicates that there is a 0.017 increase in DRAs 
per 100 square miles for every additional bear harvested. This is largely because bears tend to prey on fawns23. Therefore, if the number of bears in an area increases, mothers will move the fawns to a new location. This increased movement could lead them into other counties and across roads, hence the positive sign.

A coefficient of -0.138 for the antlerless harvest in nearby counties from the previous year indicates that there are fewer DRAs per 100 miles if hunters successfully killed antlerless deer in surrounding counties in the previous year. As stated above, antlerless deer tend to be hit on the road far more often than antlered deer. This could be an indication that there is a oneseason delay in the spillovers from antlerless permit sales.

As the population density in a county increases, deer are more likely to leave. Deer tend to be skittish and avoid people when they can. The positive and statistically significant coefficient of 0.086 supports this hypothesis. As population density in a county increases deer are driven into surrounding counties. Since their movement is being affected, they are more likely to cross roads as well, thus increasing DRAs.

The border effects variable is also positive and statistically significant indicating that an increase in the average county deer harvest of adjacent non-Pennsylvanian counties by 100 is associated with 0.326 more DRAs per 100 square miles in Pennsylvanian counties neighboring the border county. Deer hunting is exceedingly popular in neighboring states like New York and Ohio.

Finally, there is a somewhat surprising result for the spillover from non-resident antlerless permits. It is positive and statistically significant indicating that for every additional antlerless permit purchased by a non-resident in a county there is a 0.045 increase in DRAs per 100 square miles in the surrounding counties. Several scenarios could cause this. First, nonresident antlerless hunters do not exist in numbers sufficient to harvest deer effectively. Additionally, they are often unfamiliar with the terrain and may be simply scaring deer away without effectively eliminating them. Finally, the report (bang) of the gun they are using may be

\footnotetext{
${ }^{23}$ Fawns are recently born deer.
} 
scaring deer even if they effectively harvest the one they shot at. This would potentially force deer to flee into surrounding counties.

The total effect is the sum of the direct and indirect effects. The SDM allows direct and indirect effects to have opposite signs and when this means their total, effect is often statistically insignificant. The antlerless harvest from last year, population density, border effects, deer population, and non-resident antlerless permit sales all have statistically significant total effects.

For a more meaningful interpretation, we can assign monetary costs and benefits to each of these results. For example, the average cost of a deer vehicle collision in Pennsylvania according to State Farm is $\$ 3,400$. Our results suggest that 0.129 additional DRAs occur per 100 square miles for every additional 100-bow permits that are sold. The average area of a Pennsylvania county is 668 square miles. This means that there are 0.86 more DRAs in the average PA county per 100 bow permits sold. This equates to $\$ 2,924$ in damages per 100 bow permits issued in the average Pennsylvania county. Now there are benefits that offset this cost. Hunting license cost for a bow permit is $\$ 29$ (\$19 for the general license and $\$ 10$ for an archery stamp). This means that the state gains $\$ 2,900$ in revenue for every 100 bow permits sold. That still means that after accounting for the benefits the state is losing $\$ 24$ for every 100 bow permits issued.

\subsection{Discussion}

Based on this analysis, hunting methods do have an effect on DRAs in a county. Antlerless permits negatively correlate with deer-related auto accidents within a county while bow permits are positively correlated with DRAs within a county. This is directly contrary to previous literature that suggests bow hunting is a viable and effective technique. ${ }^{24}$

In theory, hunting techniques could impact DRAs in neighboring counties. However, this analysis did not find any significant spillover effects of hunting techniques on DRAs per 100 square miles in neighboring counties. This study did find that the bear harvest and the human population density in a county did have significant positive spillover effects on DRAs in

\footnotetext{
${ }^{24}$ See Krueger, W. J., McAninich, J. B., \& Samuel, D. E. (2002). Retrieval and loss rates of white-tailed deer by Minnesota bow hunters. In Proceedings of the First National Bow hunting Conference. Archery Manufacturers and Merchants Organization, Comfrey, Minnesota, USA (pp. 76-84).
} 
neighboring counties. Apparently, deer feel pressured from both humans and bears. If those populations increase, the deer move into surrounding counties and increase the number of deerrelated car accidents there. Non-resident antlerless permits also increased the DRAs per 100 square miles in neighboring counties. This means that the push by the PGC for more nonresidential hunters in the state may be having an unintended effect of increasing DRAs in surrounding counties. The number of antlerless deer killed in the previous year was also correlated with a decrease in surrounding areas DRAs per square mile.

Based on these results, if states want to reduce the number of deer-related auto accidents, they could do a number of things. First, states could either reduce the number of bow hunters in the state or make bow hunters more efficient. Encouraging the use of crossbows by archery hunters could increase the effective range and lethality of bow hunters. In addition, to reduce deer-related auto accidents in a particular county, states could increase the number of antlerless permits in that county. However, another possible solution might be to make policy decisions to reduce the number of bears in surrounding counties or increase the number of antlerless deer harvested in surrounding areas. These could be effective ways of limiting DRAs within specific counties. While bow hunting may possibly be the most "sporting" way to hunt, it is the least efficient way of reducing DRAs.

\subsection{Bear Hunting and the Spillovers of Bear Property Damages in West Virginia: Introduction}

The black bear has made an amazing recovery in Appalachia after being on the brink of extinction in much of Appalachia prior to the 1980s (NBBTC, 2012). Figure 3 below shows the current range of black bears. The animal's population has started to expand through areas where they have not existed since the 1800s (Bertalan \& Bertalan, 2015). Forest regeneration and proper wildlife management have guaranteed the future prosperity of this large game animal (NBBTC, 2012). However, further human expansion into forested habitat and increasing bear populations have resulted in animals living very near to residential areas. Unfortunately, this

proximity can lead to negative encounters between bears and people. The most common of these are vehicle collisions and property damage (Baruch-Mordo et al., 2008). Property damage often occurs when bears are drawn to human food sources (NBBTC, 2012). Additionally, after gaining 
access to human food, some bears associate people and their property with sustenance ${ }^{25}$. This remains the root cause of nuisance bear activity (Ryan et al., 2007).

\section{Figure 3: Range of the North American Black Bear ${ }^{26}$}

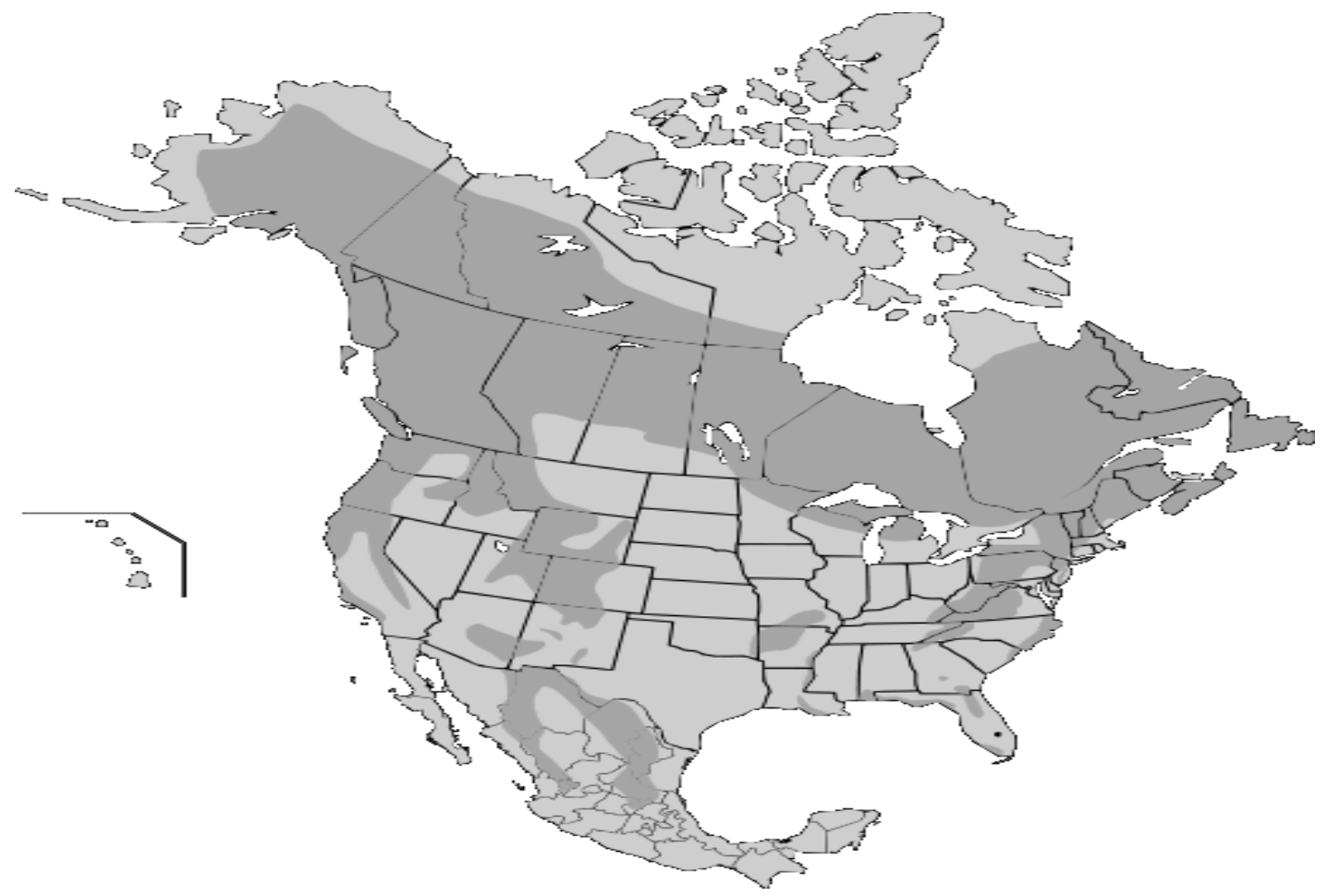

Problems associated with increasing black bear populations are becoming prevalent in the Eastern US. Black bears in Maryland were historically abundant because of the excellent habitats provided by the state's woodlands. However, after years of hunting, trapping, and human expansion, the black bear population suffered. Maryland's last black bear hunting season took place in 1953 (Neuland, 2011). By the mid-1960s, the black bear population was nearly gone and was restricted to the more remote mountainous areas of Allegany and Garrett counties. In 1972, the status of the black bear changed from that of a "forest game" animal to an "endangered species" in the state (Neuland, 2011). As a result, the population began to recover. A 1991 population study in Maryland estimated 79 bears in Garrett County (12.0 bears per 100 sq. mi.) (MD DNR, 2015). While in 2000, DNR conducted another population study that estimated 227 adult and sub-adult bears (27.3 bears per 100 sq. mi.) in Garrett and Western Allegany counties. This study demonstrated that bears clustered in adjacent Pennsylvania counties where 21.7 bears

\footnotetext{
${ }^{25}$ Bears will search bird feeders, garbage cans, pet food supplies etc. for

${ }^{26}$ Source: Gov't of Manitoba
} 
per 100 sq. mi. were reported (MD DNR, 2015). In 2006, Maryland opened a limited lottery hunt for black bears in 2004 for the two counties with the largest bear densities. This limited hunt has continued in a similar fashion to the present.

After this first annual hunt, in Maryland, there was a conspicuous rise in the number of bears harvested in surrounding counties in Pennsylvania and West Virginia. This could be a reflection of increasing populations of bears. An increase in the bear population could lead to an increase in property damages caused by black bears (Ryan et al., 2007). It follows that if populations of bears are spilling over into adjacent areas, bear damages could increase. These damages include ripping open trashcans, destroying beehives, breaking into houses, and killing pets. Damages from black bear can range in cost to individuals from $\$ 40$ to over $\$ 5,000$ (Vaughan et al., 1989). The Pennsylvania Farm Bureau Director, Jeff Grove, told the Pennsylvania Game Commission in 2004 that a particular farm in Warren County had suffered \$15-25,000 worth of crop damage from bears (Grove, 2014).

The State of West Virginia imposed bounties on several predators at various times in history. Pendleton County, for example, paid a bounty on bears at various times beginning in 1928. Randolph County permanently discontinued the bear bounty system in 1953 and the black bear was finally designated a game animal by the 1969 legislature, at which time Pocahontas County discontinued its bear bounty system (Cromer, 2002). At the same time, Maryland was reopening its black bear hunting season, West Virginia started to notice issues associated with larger bear populations. The address this, the state offers a compensation program for bear damages and, after a few years of higher than usual bear damage claims, they decided to take action. In 2008, West Virginia expanded its black bear hunting season. Bear hunting now overlaps with some of the deer-hunting season in the state (Ryan et al., 2009).

This research seeks to determine the impact that different hunting methods have on bear damage claims. ${ }^{27}$ Could hunting methods affect the movement of black bears? If a black bear must move away from a food source, it may seek out easy to obtain meals such as corn, garbage,

\footnotetext{
${ }^{27}$ This research identifies bear damages as real property damage done by black bears. This includes but is not limited to beehive destruction, crop damage, trash can damage, and loss of livestock. Bear damage claims are requests for monetary compensations by a state for damages associated with the state's bear population (NBBTC, 2012). This research does not focus on damages occurring due to bear-vehicle collisions at this time.
} 
livestock, or even pets. This research also attempts to identify spillovers effects related to these different hunting methods. Observed changes in state hunting rules or practices may have spatial impacts outside the boundaries of the state. This analysis represents an improvement over previous research, which has neither separated the effects of different hunting methods nor included spillover effects of bear related property damage. Using spatial econometric techniques, this analysis finds that different hunting methods impact bear damage claims and nuisance phone calls differently. ${ }^{28}$ Additionally, hunting not only impacts the county where hunting takes place but also surrounding regions.

\subsection{A Brief History of Black Bear Management}

Prior to the arrival of the first settlers from Europe, the black bear roamed nearly the entirety of North America (Hristienko \& McDonald, 2007). To Native Americans, the black bear provided a valuable source of thick hides for clothing and shelter, and a steady supply of meat (Bertalan \& Bertalan, 2015). The unique traits, (such as its ability to hibernate) of the bear itself even provided the essence of several legends (Bertalan \& Bertalan, 2015).

Settlers brought with them European ideas about to tame and conquer the wilderness. This new wilderness had a threatening atmosphere, and so did the resident wild animals. Bounties placed on predators became common, such as the one-penny bounty of 1630 for a dead wolf in Massachusetts Bay Colony (Bertalan \& Bertalan, 2015). To the settlers, bears were predators no better than a wolf and posed threats to their way of life. This attitude surfaced in popular nature books of that time that showed animals such as bears attacking hunters or eagles flying off with children (Bertalan \& Bertalan, 2015). Settlers did not just kill bears with their guns. Cutting, burning, and clearing of land changed the wooded lands into open farm fields and pastures (Bertalan \& Bertalan, 2015).

As the human population grew and expanded, black bears lost much of their home ranges. The few black bears that remained in the Eastern US during this time were hunted for their hides, meat, and fat with little regulation (Bertalan \& Bertalan, 2015). Bears reproduce rather slowly and this makes recovering from over hunting nearly impossible without controls.

\footnotetext{
${ }^{28}$ Nuisance phone calls are calls made to a state's Department of Natural Resources regarding nuisance wildlife. Some states, like West Virginia, separate these calls out by species.
} 
By 1900, black bear bears were nearing the point of extinction in the Northeastern US (Hristienko \& McDonald, 2007). This is an example where economic users withdraw resources to secure short-term gains without regard for the long-term consequences, and lead to the term "tragedy of the commons".

A tragedy of the commons issue was avoided when Americans realized the importance of wildlife management, including the plight of the black bear. If access is regulated by restricting extraction or harvest and by imposing limits to the quantity of goods being withdrawn, the tragedy of the commons may be avoided. By the mid-1900s, hunting seasons include heavy regulations. At the same time, restoration programs for black bears began in some states (MD DNR, 2015). Since 1960, forests in West Virginia are also making a slow but steady resurgence (Ryan et al., 2007). Black bears started to return to the state in abundance around this time. Beginning in the late 1980s, black bear numbers increased at a rate of two percent per year continent-wide, with some states such as New Jersey and Maryland reporting a five-fold increase (Bertalan \& Bertalan, 2015).

Though black bears have not reclaimed their pre-colonial range across North America, their populations have rebounded to an estimated 800,000 bears in 37 states and Canada (Government of Manitoba, 2014). Additionally, more states report black bears inhabiting areas where they have not appeared for almost 100 years (Hristienko \& McDonald, 2007). However, humans continue to move into prime bear territory. Today, black bears and humans compete for similar areas (Hristienko \& McDonald, 2007).

One particular issue is that the biological carrying capacity of various habitats can sometimes support more black bears in an area than humans will tolerate. This tolerable number is the cultural carrying capacity. ${ }^{29}$ States use a variety of methods and techniques to attempt to mediate potential conflicts between bears and humans (Bertalan \& Bertalan, 2015). For example, if the population of bears living near humans exceeds the number these humans desire, biologists might trap and relocate some bears to a new area. While this strategy has very limited effects on the real issue of the overall population, it does appease local populations (Hristienko \& McDonald, 2007). Public education about sharing the land with black bears can affect the

\footnotetext{
${ }^{29}$ This number is often less than the biological carrying capacity,
} 
cultural carrying capacity in an area by making humans more tolerant of increasing black bear populations (Hristienko \& McDonald, 2007).. ${ }^{30}$ Hunting may also be used to keep bear populations within the cultural carrying capacity. ${ }^{31}$

\subsection{Literature Overview}

Bows and rifles are the two common hunting implements used to harvest black bears in the United States (Hristienko \& McDonald, 2007) ${ }^{32}$. Each implement has its own dedicated set of hunters. However, bow hunting has recently come under scrutiny because of poor hunting results. The literature regarding bow hunting accuracy and wounding rates involve has focused exclusively on deer. One could assume that these results scale up for larger animals with thicker hides such as bears. Boydston \& Gore (1987) indicated that shot placement for an arrow in hunting (in general) is for all practical purposes random. Using data collected from 3,568 deer hunters in Texas over a thirteen-year period, they found that bow hunting results in a wounding rate of over $50 \%$ and that more than 21 shots were needed per deer killed. In comparison, gun hunters only had a wounding rate of $7 \%$ (Boydston \& Gore, 1987). The authors indicate that these results reflect the fact that bow hunting is an extremely demanding sport. A hunter as close as 30 yards from a deer, fire the arrow undetected, and hit the vital areas of the animal for a quick kill (Boydston \& Gore, 1987). This inaccuracy is not solvable. Gladfelter et al. (1983) reported that crippling is not correctable by increased training or field experience and is a byproduct of the sport. This is because arrows fly in a looping trajectory. Bullets on the other hand have a linear path (Kaiser, 1986) ${ }^{33}$. In light of these facts, wildlife biologists indicated that bow hunting is not an effective wildlife population control measure (Kilpatrick et al., 2002). The inevitable conclusion is that bow hunting is far more difficult and less effective compared to hunting with a gun.

In addition to hunting, states can compensate the public for losses caused by bears. These programs have expanded from only 10 states in the 1950s (McDowell \& Pillsbury, 1959) to 32

\footnotetext{
${ }^{30}$ This does not address the issue of nuisance bears. This merely is an attempt to reduce the number of further nuisance bear complaints.

${ }^{31}$ It is difficult to obtain permission to hunt any animal in residential areas in the United States. Bow hunting is the primary method used when hunting is allowed near residential areas. West Virginia resident landowners in rural areas may hunt on their own land without obtaining a license.

${ }^{32}$ Other methods include trapping bears, using dogs to hunt bears, and baiting bears. All of these methods still use a bow or a gun to kill the bear. Data is also very limited concerning how many hunters actually partake in these activities.

${ }^{33}$ While these studies focused on archery and deer, the results do translate to bears. In fact, the numbers are most likely worse considering that all bears have a thick layer of fat that protects them.
} 
today. Compensation programs reduce the risk of direct injury to humans and wildlife from traps and pesticides, which homeowners use to deal with the problem on their own, and may increase landowner tolerance of problems with threatened or endangered species (Olsen, 1991).

Compensation also may be a useful tool in situations where private lands include, or are adjacent to, habitat critical for the well-being of a wildlife species or population (Van Eerden, 1990; Olsen, 1991; Rimbeye et al., 1991). Payment programs exist in areas where the public places a high monetary value on game species. License revenues fund wildlife management programs and pay for damages caused by game species (Engle, 1963; Rimbeye et al., 1991). This is alarming because a new survey by the U.S. Fish and Wildlife Service shows that today only about $5 \%$ of Americans, 16 years old and older, actually hunt. That is less than half of the hunters from 50 years ago and the decline should accelerate over the next decade (Rott, 2018)

However, not all opinions regarding compensation programs are positive (Olsen 1991). McIvor and Conover (1994) asked northern Utah and southern Idaho farmers and non-farmers their opinions of hunting and compensation as solutions to damage caused by sandhill cranes. Both farmers and non-farmers had a higher approval of hunting than of compensation programs. $69 \%$ of farmers and $50 \%$ of non-farmers approved of hunting, whereas only $32 \%$ of farmers and $23 \%$ of non-farmers approved of compensation programs. Additionally, compensation programs rarely pay producers for the full value of all direct and indirect costs associated with wildlife damage. For example, from 1982 to 1991 , Utah allocated an average of $\$ 50,000$ annually to be distributed in order to compensate residents for wildlife damages, which was less than $50 \%$ of the market value of the damages (Olsen 1991). However, at a time of increasing budget constraints, the financial burden of compensation programs may be unacceptable (Van Eerden, 1990; Olsen, 1991; Rimbey et al., 1991). In a 1990 survey of programs for crop damage by large mammals, Wisconsin reported payments for compensation and damage prevention materials averaging $\$ 920,000(\$ 1,752,652.79$ in $2018 \$)$ per year and almost $\$ 2,350,000(\$ 4,476,884.85$ in 2018\$) in some years (Wagner, Schmidt, \& Conover, 1997). Additionally, Idaho paid \$500,000 (\$952,528.69 in 2018\$) in claims for damage occurring from July to December 1988 (Rimbey et al., 1991).

One area of uncertainty is how far does a bear actually travel? There was fear that increasing human numbers have resulted in fragmentation and isolation of southeastern bear 
populations (Maehr, 1984). Further, wide-ranging species such as black bears have expansive habitat requirements (Harris, 1984). Black bears prefer soft mast, such as, blueberries, black cherries, and blackberries (Hellgren, 1991). Bears also enjoy wetland areas and tend to thrive in these environments (Hellgren, 1991) ${ }^{34}$. There are many estimates for how far a black bear ranges. These estimates usually do not take into account outside influences (Ordiz et al., 2012) ${ }^{35}$. Anecdotally, one Florida bear traveled 87 miles $(140 \mathrm{~km})$ over the course of a single month (Maehr et al., 1988). The behavior of this bear seems typical of many nuisance bears in Florida. Male black bears most commonly engage in disturbances around apiaries, livestock, garbage, and other human attractants (Ryan, 2007). Undoubtedly, the increased presence of humans around these bear population fringes increases the likelihood of bear-human encounters. Pelton (1982) observed, "The comparatively high intelligence of the species and the emotions it evokes in people combine to present a singular dilemma for responsible resource agencies." Clearly, the perceived need for protection of human life and property versus the ecological or aesthetic value of a single wild animal is a difficult management problem.

The majority of states use regulated hunting seasons to manage their black bear populations (Hristienko \& McDonald, 2007). Previous investigators have indicated that sport hunting can alter populations of black bears by reducing population size and average age (Cowan 1972; Bunnell \& Tait, 1985). However, hunting can impact animals in unintended ways. Male bears range over larger areas than females (Pelton, 1982) and therefore are more likely to encounter hunters than are female bears (Bunnell \& Tait, 1985). Yet this differential vulnerability also is a function of two characteristics of hunters' mobility and selectivity. For example, as hunters move over larger areas (e.g., by using trained hounds), the effects of different ranges of male and female bears are reduced, and hunter harvests should approximate the composition of the bear population (Bunnell and Tait, 1980). Research in Scandinavia has found that hunting can force prey animals to become more alert and can influence distribution and habitat use even more than natural predators (Ordiz et al., 2012). In their article, "Do Bears Know they are being Hunted" (2012), Ordiz et al. studied the movement of brown bears in Scandinavia before and after the start of the annual bear hunting season. They expected that

\footnotetext{
${ }^{35}$ Such as hunting, trapping, and other human activities.
} 
because of shortening daylight hours bears would become more active as the season progressed. However, the start of hunting disrupted this pattern. Solitary bears subject to hunting decreased their nocturnal rest and increased movements during the dark after hunting began. Even females with cubs born that year ${ }^{36}$ modified their movement patterns (Ordiz et al., 2012). These authors believe that behavioral effects of hunting should be a relevant issue for the conservation and management of large carnivores (Ordiz et al., 2012).

Other areas of human development play a role in the prevalence of nuisance bears. Roads frequently appear as factors affecting black bear behavior and habitat quality in the southeastern United States (Pyke, 1981). In areas open to hunting, bears avoid roads (Reiffenberger, 1974; Hamilton, 1978). Animal movement patterns are tactics that tend to optimize the efficiency of habitat exploitation subject to physical, ecological, and social constraints (Pyke, 1981; Anderson, 1983). Lewis et al. (2011) found that when bears crossed the highway they selected for specific habitat attributes, at both roadside and landscape scales. These were characterized by forested areas away from human development, with additional important habitat features including distance to cover, amount of shrub along the highway, and distance to water (Lewis et al., 2011). If highways split a bear's home range, they are more likely to cross roads. Baruch-Mordo et al. (2008) noted that 11 out of 23 black bears fitted with GPS collars crossed the highway at least once. Bears use road margins for feeding on important plants in their diet (Hellgren, 1991). Additionally, Baruch-Mordo et al. (2008) found that more the one-quarter of damages associated with black bears are from to bear-vehicle collisions. The risk of mortality on roads is part of most habitat-use-models as a constraint (Milinski \& Heller, 1978).

Additionally, given the range of bears, previous research has failed to determine if the hunting policies of one region affect other surrounding regions. However, there has been no previous research on this. The crime literature concerning the spillover of crime may give insights into this issue. Just as bears destroy property, criminals commit crimes. Criminals move when law enforcement or other deterrents increase in an area. Lott (1998) investigated whether the adoption of a concealed-weapons law in one state alters crime in neighboring areas and both Lott and David B. Mustard (1997) found a strong local deterrent effect of the law. Some research

\footnotetext{
${ }^{36}$ Females with cubs are protected from hunters in Norway (Ordiz et al., 2012).
} 
has addressed the issue of what happens if crime moves elsewhere (Bartley \& Cohen, 1998; Lott, 1998). These studies give insight into how bears may react if hunting or deterrents increase in an area. While bears are obviously not as intelligent as humans are, they certainly respond to incentives. Spatial econometric methods can be used to determine how the hunting practices of one region affect neighboring areas. Understanding this can make wildlife management practices more effective.

\subsection{Data/Model}

The area of interest in this study is West Virginia. West Virginia has an extensive history of black bear management and regularly deals with issues related to black bears. Its Department of Natural Resources (DNR) publishes bear harvest and damage complaints at the county level. To hunt bears in West Virginia, a licensed hunter must have a bear damage stamp issued by the Division of Natural Resources (Ryan, 2007). ${ }^{37}$ The fee for the stamp is $\$ 10.00$. All sales of stamps go to the bear damage fund, which is maintained by the DNR and used to pay property owners for damages to property caused by bears (Ryan, 2007). This fund also covers the expense for black bear research programs within the state (Ryan, 2007). ${ }^{38}$ If people have property damaged by a bear, they can submit a damage claim to West Virginia's DNR for investigation. If approved, the individual receives compensation from the bear damage fund.

The two units of measurement for the dependent variable in this study is the number of claims paid in a given year and the number of nuisance bear phone calls to WVDNR. ${ }^{39}$ These individuals call WVDNR and complain that a bear is destroying property or acting aggressively. They are not submitting damage claims merely using a pseudo tip line. Nuisance phone call data were constructed by weighting the known nuisance phone call total of the state with forest coverage and mast production. This was used to disaggregate the total nuisance phone calls for the state down to the county level. ${ }^{40}$

A panel of data was constructed consisting of all 55 counties in West Virginia for the years 2005-2013. ${ }^{41}$ A map of the average number of annual claims submitted to West Virginia's DNR by county is shown below in figure 4 . The majority of bear damage claims occur in the

\footnotetext{
${ }^{37}$ Hunters are issued one stamp and may apply for another only if they successfully kill and report a black bear.

${ }^{38}$ The proportion of the fund that goes to research is unknown at this point.

${ }^{39}$ Not all damage claims receive compensation payments from the state.

${ }^{40}$ Anywhere from 4 to 7 county totals are published each year. These were used to inform the disaggregation.

${ }^{41}$ Harvest data were not separated by hunting method in West Virginia before 2005.
} 
southeastern section of the state. ${ }^{42}$ Randolph County typically has the most bear damage claims per year. Given that there is a large national forest right below Randolph and West Virginia borders the Ohio River to the West this is not surprising.

Figure 4: Average Annual West Virginia County-Level Filled Bear Damage Claims (2005 2013) 43

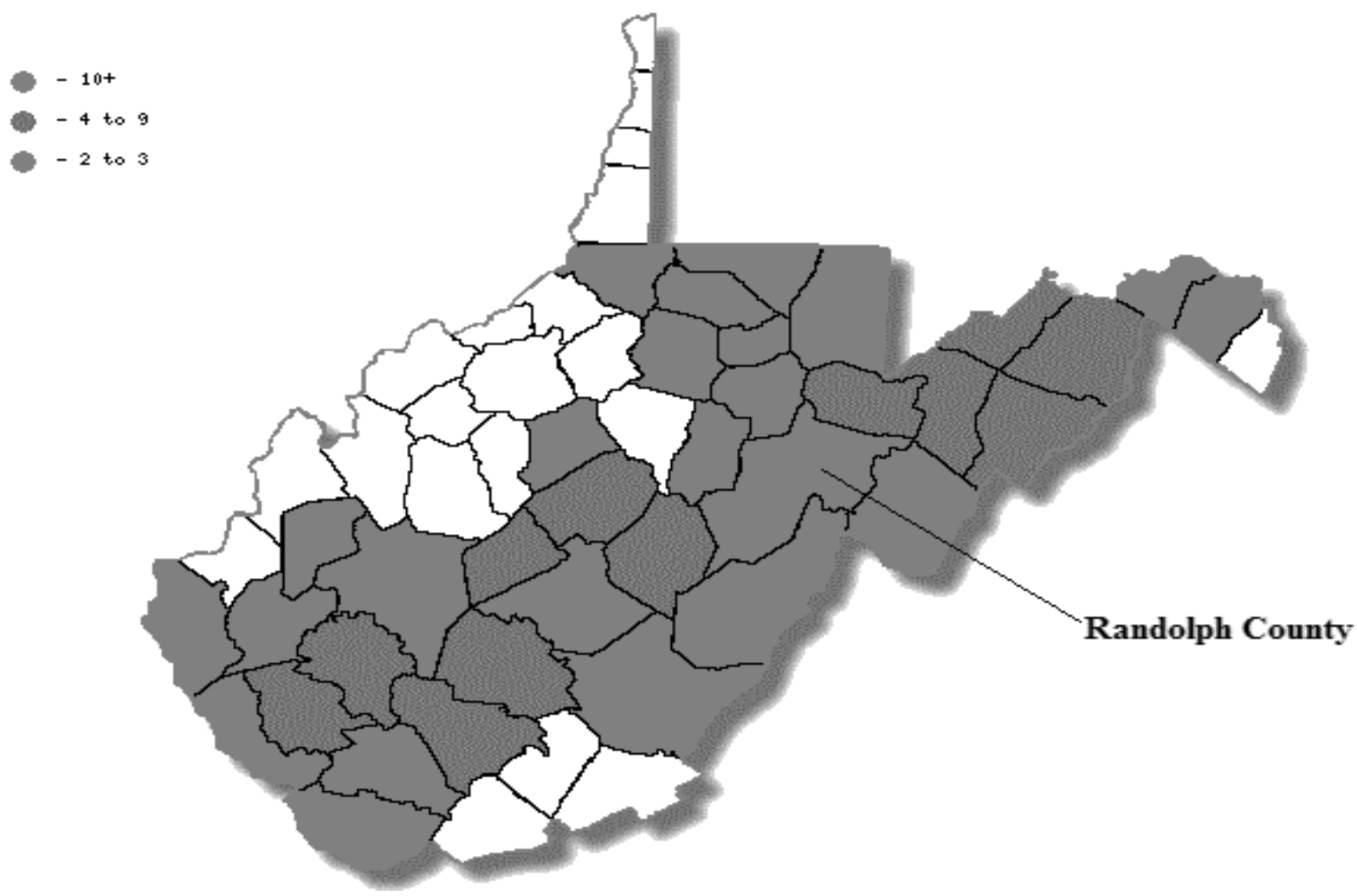

Figure 5 below shows the average black bear harvest in each county of West Virginia (2005-2013). The majority of the harvest also occurs in the southeastern part. Randolph and Nicolas County typically harvest the most bears each year. However, damage claims do range into areas where little hunting occurs.

\footnotetext{
${ }^{42}$ The Ohio River borders the Northwestern part of the state and creates a natural boundary for black bears.

${ }^{43}$ This map was generated using data from West Virginia's DNR Big Game Bulletin publication (2005-2013).
} 
Figure 5: West Virginia Average Annual County Bear Harvest $\left(2005\right.$ - 2013) ${ }^{44}$

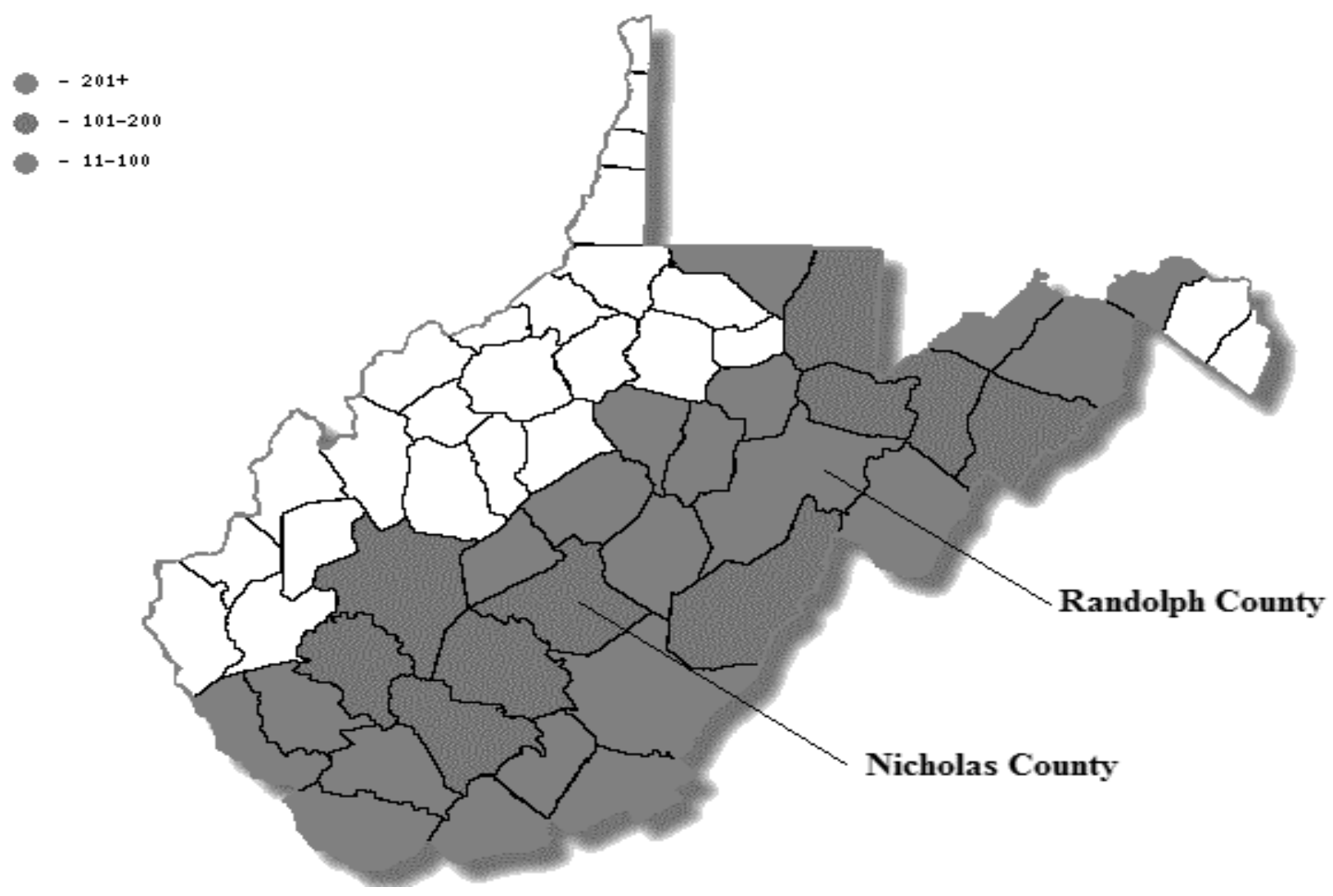

These two maps seem to show that bears are responding to hunting pressure. Clearly, there are differences in hunting popularity in West Virginia counties. These reflect the different attitudes represented in each county. Bears are responding to these differences by moving. Traditional methods of observing movement fail here because bears are not subject to political boundaries $^{45}$. Moreover, while radio collar studies are useful, the total number of bears with radio collars is strikingly low compared to the hypothesized overall population (Ryan, 2007) ${ }^{46}$. Previous research has failed to determine if the hunting policies of one region affect other surrounding regions. Additionally, because there are few reliable ways to track the population of black bears as a whole, spatial econometric techniques may be a useful way of observing the movement bear populations by tracking the effect they have on their surroundings. While the

\footnotetext{
${ }^{44}$ This map was generated using data from West Virginia's DNR Big Game Bulletin publication (2005-2013).

${ }^{45} \mathrm{~A}$ bear does not realize it has moved from Clay to Braxton County or from West Virginia to Maryland/Virginia.

${ }^{46} 21$ radio collared bears in 2007 compared to a hypothesized population of 10,000 to 12,000 bears. In addition, radio collars are designed to fall off of the bear in 100 weeks (Ryan, 2007). These radio collared bears were all female and from the southern section of the state.
} 
information gained from these few bears with radio collars is useful, it is not a good reflection of the total population.

\section{Figure 6: West Virginia Counties That Complain About Bears}

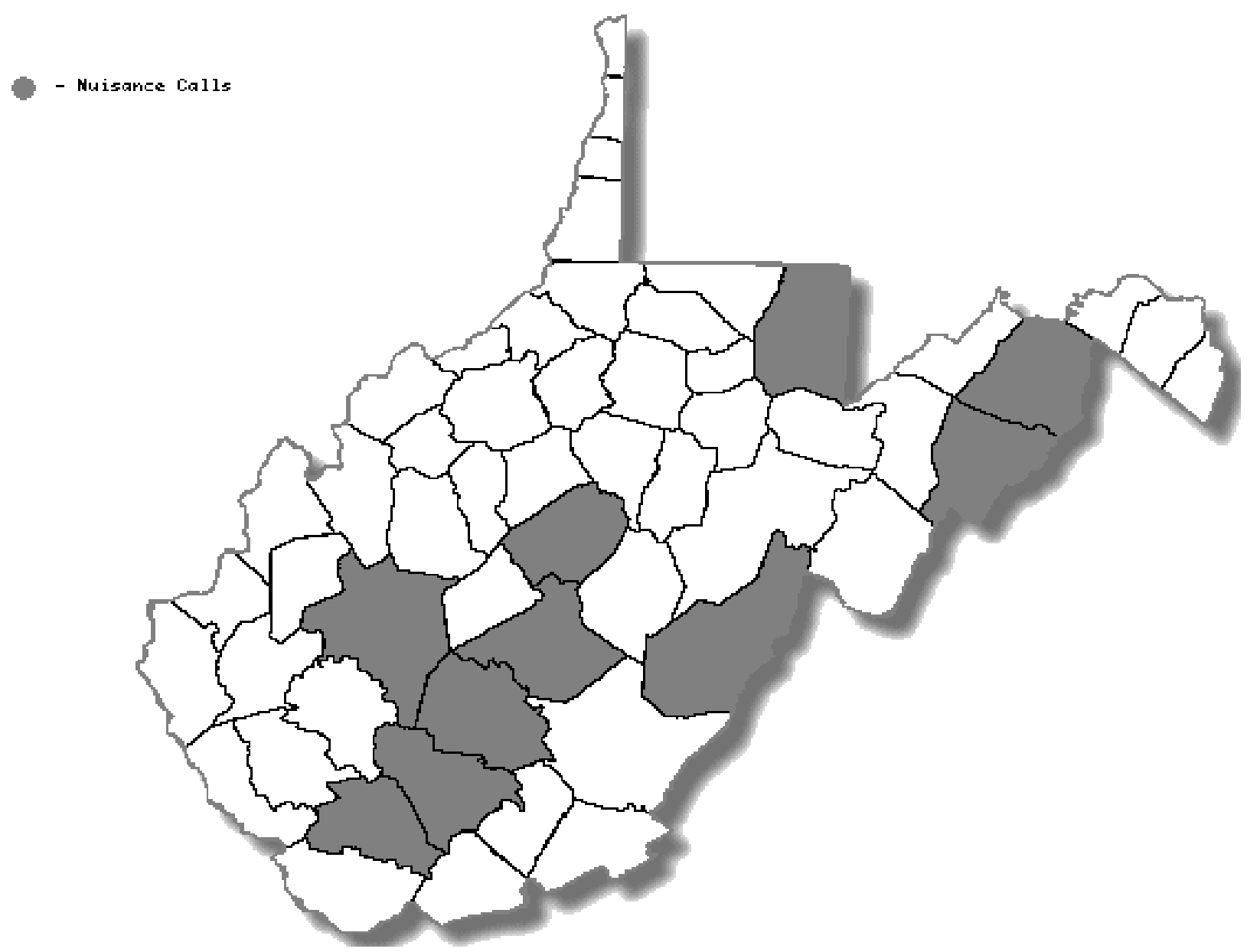

Figure 6 above highlights the counties that have appeared in the top counties by nuisance phone call list the WVDNR publishes each year. Interestingly, a selection of counties that complain a great deal about bears are neither hunting them excessively nor receiving much compensation from the state. ${ }^{47}$

The literature suggests that food availability, number of bears harvested, and wildlife management techniques all influence bear nuisance complaints and bear damage claims (Van Eerden, 1990; McIvor \& Conover, 1994; Hristienko \& McDonald, 2007; Ryan et al., 2009). Eight explanatory variables are included. The first two deal with hunting techniques. What is the

\footnotetext{
${ }^{47}$ West Virginia's Big Game Bulletin is published every year and lists the top five counties by nuisance phone calls and the total amount of nuisance phone calls received that year.
} 
impact of different bear hunting methods? Three different outcomes of interest could exist. First, ineffective hunting methods could be scaring bears into the border counties of neighboring states (or just bordering counties). These regions would then have to deal with the issues associated with larger bear populations. On the other hand, some effective hunting methods could be contributing to a reduction of bear related property damages in border counties by reducing the number of bears that reside close to state borders. If this is the case, bear hunters in affected counties may be upset because they have a lower chance of harvesting a bear. The least interesting result is that hunting is having no effect.

The first variable included is the number of bears harvested using a bow ${ }^{48}$. This variable could increase bear damage claims. While it does have the advantage of being quiet, it sacrifices lethality, range, and ease of use and is therefore less effective than hunting with a gun (Boydston $\&$ Gore, 1987). People entering the woods with ineffective equipment are most likely scaring or merely injuring bears. Therefore, bow hunters could be influencing bears to move more. These scared bears might be more likely to seek out an easy meal on a farm rather than hunt where the hunters are. Injured bears would also be more likely to search for an easier meal because there movement is restricted.

The second key variable is the number of bears harvested using a rifle. Contrary to bow hunting, hunting with a rifle is relatively easy (Kaiser, 1986). A gun is also lethal at longer ranges than a bow. Therefore, while bears are certainly scared of rifle hunters as well, they should be more effective at harvesting bears. This variable should reduce bear damage claims ${ }^{49}$. It does however make a very loud noise when fired, which means scaring bears is still a possibility.

Another variable included is farm employment in each county. This becomes a proxy for farmland in the county. More farm employees could be related to more farmland. Farms are particularly attractive to bears. Not only do they provide easy to gather vegetation (corn, berries, honey, etc.) but they provide easy prey items in the form of domesticated animals (calves, dogs, cats, etc.). In addition, farmers are more likely to complain about nuisance bears because a bear

\footnotetext{
${ }^{48}$ If hunting license sales data existed that would be ideal. However, West Virginia's DNR does not have readily available hunting license sales data at the county level.

${ }^{49}$ The loud report of a gunshot could scare bears as well. However, the assumption is that the overall effect would still be negative because the gun hunters are more effective at killing bears.
} 
can affect a farmer's livelihood (Ryan et al., 2009). Bears can destroy crops, injure livestock, and disrupt fences, in addition to wrecking garbage cans. The hypothesized impact of this variable is to increase bear damage claims. ${ }^{50}$

The next variable in the model is the population density of each county. Very dense populations could indicate urban areas, which are less likely to have black bear issues. However, sparser populations (rural or suburban) could be more likely to experience bear related issues. Areas with dense populations of people would not be attractive to bears. There is less forestland and less available food. In addition, like any wild animal, bears are naturally afraid of humans. Therefore, it hypothesized that this variable would decrease bear damage claims.

Clearly, some measure of food availability in a county should be included. While these data are not readily available, WV DNR does publish an annual mast survey (food available for woodland animals) but this contains limited information. ${ }^{51}$ What is derived from this survey is if mast production increased from the previous year. Therefore, the mast production measure in this study is a dummy variable ${ }^{52}$ ( 1 if there is an increase in mast production from the previous year; 0 otherwise ${ }^{53}$ ). More mast production could mean that bears have readily available natural food and would relate to less nuisance bear problems.

An interesting case can be made for the hunting effectiveness of poachers. They tend to use the most effective method to hunt whatever animal they choose. For bears, this includes using dogs in a non- designated dog-hunting county, hunting from a car, and using bait to draw in bears. While illegal, these methods are all effective (McLaughlin \& Smith, 1990). WV DNR tracks bears illegally killed at the county level, which are included as it is thought that this would reduce bear damages.

\footnotetext{
${ }^{50} \mathrm{~A}$ better variable to use would be farmland or amount of particular crops harvested like corn or soybeans in a county.

${ }^{51}$ West Virginia's Annual Mast Survey is separated into six regions with each region comprised of multiple counties. WVDNR sends surveyors out to establish the amount of mast producing trees in that area each year. For more information about these surveys, please see WVDNRs Mast Production Surveys in the references section. To obtain data for each county it is assumed that whatever happened in the region, happened in each county contained in that region. While this assumption is most likely untrue, it was the best option available at the time.

${ }^{52}$ An alternative method that may be explored is to determine if that year was an increase or decrease from the average mast production in the state over the period 1972-present. This data is available and could be superior to the dummy for if mast production increased from the previous year.

53 If the mast production that year did not change from the last year, it is counted as a decrease (0).
} 
Marauding bears are bears that exhibit marauding behaviors including trash-raiding, human safety concerns, and preying upon domestic animals. WV DNR publishes the number of bears they kill each year at the county. Certainly reducing the number of marauding bears in a county would reduce the number of bear damages in that county.

The literature indicates that a measure for highway traffic is important in this analysis. More traffic in a county could either drive bears away from roads and into other surrounding counties or result in more bear deaths due to collisions (which we leave for future research). West Virginia's Department of Transportation provides data for total daily vehicle miles travelled on highways in each county. ${ }^{54}$ Table 1 below shows the summary statistics for the variables discussed in the above text.

While a measure for edge effects would be ideal for this analysis the data limitations prevented it from being included at this time. Data concerning bear hunting is limiting in various states surrounding West Virginia. This includes, total harvest, permits, and permit types.

Table 3: Summary Statistics (Bear)

\begin{tabular}{|c|c|c|c|c|c|c|}
\hline Variable & Mean & $\begin{array}{c}\text { Standard } \\
\text { Deviation }\end{array}$ & Range & Minimum & Maximum & Count \\
\hline $\begin{array}{c}\text { Claims (Per Sq. } \\
\text { Mi.) }\end{array}$ & 0.006339 & 0.008472 & 0.055359 & 0.000111 & 0.05547 & 495 \\
\hline Nuisance Calls & 19.80289 & 28.6902 & 165.7975 & 0.1 & 165.8975 & 330 \\
\hline $\begin{array}{c}\text { Bear } \\
\text { Harvest_Bow }\end{array}$ & 12.03838 & 17.6656 & 118 & 0 & 118 & 495 \\
\hline $\begin{array}{c}\text { Bear } \\
\text { Harvest_Gun }\end{array}$ & 25.90303 & 44.98572 & 245 & 0 & 245 & 495 \\
\hline Illegal Kills & 0.129293 & 0.589595 & 5 & 0 & 5 & 495 \\
\hline Marauders & 1.624242 & 4.233469 & 32.47059 & 0 & 32.47059 & 495 \\
\hline $\begin{array}{c}\text { Total Daily VEH } \\
\text { Miles (mill) }\end{array}$ & 9.610031 & 10.7056 & 70.1927 & 1.0477 & 71.2404 & 495 \\
\hline Pop Density & 96.54911 & 100.6136 & 417.0944 & 9.223848 & 426.3183 & 495 \\
\hline Mast Production & 0.452525 & 0.498245 & 1 & 0 & 1 & 495 \\
\hline Farm Emp & 396.8182 & 256.7099 & 1061 & 0 & 1061 & 495 \\
\hline
\end{tabular}

\footnotetext{
${ }^{54}$ Interstate daily vehicle miles traveled was considered but it was serially correlated with total daily vehicle miles traveled. Total daily vehicle miles traveled was included because it contained less zeros than the interstate daily vehicle miles' data. Brandenburg (1996) also pointed out that in contrast to primary roads; some bears used secondary roads as convenient travel corridors. The response/reaction behavior of bears to primary roads was more pronounced compared to secondary roads (i.e., nonpaved roads)
} 
This analysis uses spatial econometrics to determine if there are spillover effects of the variables associated with bear damage complaints and claims. Fortunately, LaSage and Pace's

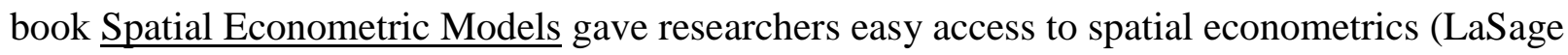
$\&$ Pace, 2010). Subsequently, several different subjects have been studied using spatial econometrics. Lacombe et al. (2014) used the 2004 U.S. presidential election to determine the potential for spatial dependence in models of voter turnout. Spatial panel models were even applied to determine cigarette demand in 46 different U.S. states (Elhorst, 2014). Elhorst also used a two-regime spatial Durbin model with spatial and time-period fixed effects to test for political yardstick competition in France (Elhorst \& Fréret, 2009). Because this model has omitted bear population numbers, the SDEM model is preferred. It has the ability to take this kind of spatial error correlation into account while other local spatial econometric models (like SLX) cannot (LeSage and Pace 2009). This model has a number of advantages (Pace and Zhou 2012). Some of the strongest advantages are that the SDEM allows for separate modeling of spillovers and disturbances, and the direct and indirect effects in a SDEM are not constrained to have the same sign. The results from estimating the SDEM are below in table 4. Finally, while $\rho$ is the spatial correlation parameter in the SAR model, $\lambda$ is the spatial error correlation parameter in the SDEM. It is positive and statistically significant. The significant $\lambda$ spatial autocorrelation parameter indicates that there is spatial error correlation that needs to be accounted for in the econometric model (Kalenkoski, \& Lacombe, 2015).

The weight matrix used in this study is a 2-nearest neighbor matrix based on county centroids. Log likelihood tests were conducted and the weight matrix with the highest loglikelihood value is found for the spatial Durbin error model with a 2-nearest-neighbours weight matrix. County and year-fixed effects are also incorporated. 


\subsection{Results}

Table 4: Spatial Panel SDEM Results Filled Bear Damage Claims (2005 - 2013)

\begin{tabular}{|c|c|c|c|}
\hline Variable & Direct Effect & Indirect Effect & Total \\
\hline Bear Harvest_Bow & $\begin{array}{c}0.000143 * * * \\
(3.59)\end{array}$ & $\begin{array}{c}0.000068 \\
(1.04)\end{array}$ & $\begin{array}{c}0.000211 * * \\
(2.32)\end{array}$ \\
\hline Bear Harvest_Gun & $\begin{array}{c}-0.000066^{* * *} \\
(-3.26) \\
\end{array}$ & $\begin{array}{c}0.000103 * * * \\
(2.68) \\
\end{array}$ & $\begin{array}{c}0.000037 \\
(-0.28) \\
\end{array}$ \\
\hline Illegal Kills & $\begin{array}{l}-0.000103 \\
(-0.21182)\end{array}$ & $\begin{array}{c}0.000171 \\
(0.17)\end{array}$ & $\begin{array}{c}0.000068 \\
(-0.02)\end{array}$ \\
\hline Marauders & $\begin{array}{c}0.000211 * * * \\
(2.49) \\
\end{array}$ & $\begin{array}{c}0.000385^{* *} \\
(2.18)\end{array}$ & $\begin{array}{c}0.000596 * * \\
(2.34)\end{array}$ \\
\hline $\begin{array}{l}\text { Total Daily VEH Miles } \\
\text { (mill) }\end{array}$ & $\begin{array}{c}0.000409 \\
(1.12) \\
\end{array}$ & $\begin{array}{c}0.000873 \\
(1.36) \\
\end{array}$ & $\begin{array}{c}0.001282 \\
(1.24) \\
\end{array}$ \\
\hline Pop Density & $\begin{array}{c}-0.000114 \\
(-1.48)\end{array}$ & $\begin{array}{c}0.000285^{*} \\
(1.81)\end{array}$ & $\begin{array}{c}0.000171 \\
(0.16)\end{array}$ \\
\hline Mast Production & $\begin{array}{c}0.001621^{*} \\
(1.69)\end{array}$ & $\begin{array}{c}-0.001702 \\
(-1.31) \\
\end{array}$ & $\begin{array}{c}-8.1 \mathrm{E}-05 \\
(0.17)\end{array}$ \\
\hline Farm Emp & $\begin{array}{c}0.000015 \\
(1.34) \\
\end{array}$ & $\begin{array}{c}0.00005^{*} \\
(1.88) \\
\end{array}$ & $\begin{array}{c}0.000065 \\
(0.19) \\
\end{array}$ \\
\hline $\begin{array}{c}\lambda=0.114 \\
(1.77)^{*}\end{array}$ & $\begin{array}{c}R^{2}=0.7017 \\
\operatorname{Corr}^{2}=0.1843\end{array}$ & & \\
\hline \multicolumn{4}{|c|}{$\begin{array}{l}\text { T-stats are in parentheses below the coefficients. Significance levels are represented by } *=90 \% \text {, } \\
* *=95 \%, * * *=99 \% \text { with } N=495, R^{\wedge} 2=0.7017 \text { and } R^{\wedge} 2 \text { adj }=0.6967 \text {. }\end{array}$} \\
\hline
\end{tabular}

Table 4 shows the results of a pooled Spatial Durbin Error Model (SDEM) with spatially lagged dependent variable, spatial and time fixed effects with 495 observations. Its $R^{2}$ value is 0.7017 due to the fixed effects absorbing a great deal of the variation. Elhorst (2010a) recommends an alternative goodness-of-fit measure based on the squared correlation coefficient between actual and fitted values. The $\operatorname{Corr}^{2}$ value is 0.1843 . The difference between the two measures indicates how much of the variation in the dependent variable is explained by the fixed effects. Results indicate the fixed effects portion of the model explains approximately $52 \%$ of the variation in the dependent variable. $\lambda$ is the spatial error correlation parameter in the SDEM and is significant (barely) and positive. This indicates that there is spatial error correlation that needs to be accounted for in the econometric model.

Direct effects indicate how a one-unit change in an explanatory variable correlates with the dependent variable in the same area. There are four statistically significant direct effects in 
this model. The first is bears harvested with a bow, the coefficient of 0.000143 indicates that for every additional bear harvested with a gun there are 0.000143 more bear damage claims per square mile in that county ${ }^{55}$.

The opposite is true of bears harvested with a gun. It has a negative and statistically significant coefficient. For every additional bear harvested with a gun there are 0.000066 fewer bear damage claims per square mile. This seems to support the idea that within a county bow hunters are ineffective at eliminating such a big animal compared to gun hunters.

Marauders have a positive and statistically significant direct effect on bear damage claims. Ryan (2007) indicated that once a bear had become accustomed to humans there was no way to stop it other than extermination. The positive sign indicates that for every additional marauder that the state has to kill there is an increase in bear damage claims. This variable was used as a proxy for the number of troubled bears in the state. However, when the state has to kill a bear it can be quite a fiasco. Even helicopters are used to kill marauding bears. Perhaps this is scaring bears more than killing the problem ones.

Mast production also has a positive and statistically significant direct effect. This means that an increase in the mast production of the region the county was included in from the previous year is associated with an increase in bear damage claims. This is contrary to what the WV DNR has stated in the past. However, this could mean that if an area has an increased amount of food availability it will draw in more bears. More bears could inevitably lead to more property destruction.

The indirect effects show how a one-unit change in an explanatory variable affects the dependent variable in surrounding areas (the spillover). There are four statistically significant indirect effects in this model. The first is bears harvested using a gun. It has a positive coefficient of 0.000103, which mean every additional bear killed with a gun is associated with an increase in surrounding counties damage claims per square mile of 0.000103 (or 0.045 more damage claims for the average WV County). This is most likely due to the report (bang) a gun makes when it is fired Bears hear this and move away from the area and potentially into other counties.

\footnotetext{
${ }^{55}$ Given that the average county size in WV is 437 square miles, this result indicates that for each additional bear harvested with a bow there are 0.06 fewer damage claims filled in the county.
} 
Marauders also have statistically significant and positive indirect effect. More Marauding bears killed in a county are associated with an increase in bear damage claims in surrounding counties. This may be capturing the effect of the methods the DNR uses to kill these bears.

The population density variable has a positive and statistically significant indirect effect. Bears generally avoid densely populated areas. So if an area begins to develop bears are more likely to move away from the area and away from humans. This would increase damage claims in neighboring counties.

An increase in farm employment in a county is associated with an increase in bear damage claims in surrounding counties. This could be a reflection of expanding farming operations. If these farmers develop the land it could displace bears into surrounding counties, thereby increasing the damage claims there.

Finally, the total effect shows how a one-unit change in an independent variable affects the dependent variable overall. Due to SDEM allowing signs to differ between the direct and indirect effects we only have two statistically significant total effects: bears harvested with a bow and marauding bears. Both are positive so an increase in either the number of bears killed with a bow or marauding bears killed by the state is associated with an overall increase in damage claims per square mile in both that county and surrounding counties.

To put these results in perspective, they are converted into actual dollar values. These compared with the value of bear hunting gives context to the results. For example, the results in table 4 indicate that for every additional bear harvested with a bow there is a 0.000143 increase in bear damage complaints per square mile. The average area of a county in West Virginia is 437 square miles so an additional bear harvested with a bow in the average WV county is correlated with a 0.06 increase in bear damage complaints. The average bear-damage-complaint in West Virginia is for $\$ 2,500$ (Ryan et al., 2009). This means that $\$ 150$ additional damages are associated with a bear harvested using a bow. A hunter does pay \$50 in West Virginia to hunt the bear and the average yearly damage done by a bear is about $\$ 23{ }^{56}$ So a killed bear has gained the

\footnotetext{
${ }^{56}$ West Virginia residents pay $\$ 40$ for a general hunting license and $\$ 10$ for a bear stamp. The current hypothesized population of black bears in West Virginia is 10,000-12,000 bears. The average number of damages paid for by the bear damage fund is $\$ 230,000$. This results in $\$ 69-\$ 73$ worth of damage for each black bear.
} 
state $\$ 50+\$ 23=\$ 73$. This compared to the cost of $\$ 150$ means that each bear harvested is costing the state about $\$ 77$.

Table 5: Spatial Panel SDEM Results Nuisance Phone Calls (2005 - 2013)

\begin{tabular}{|c|c|c|c|}
\hline Variable & Direct Effect & $\begin{array}{l}\text { Indirect } \\
\text { Effect }\end{array}$ & Total Effect \\
\hline Bear Harvest_Bow & $\begin{array}{l}0.080591 * * * \\
(5.91)\end{array}$ & $\begin{array}{c}0.010868 \\
(0.48)\end{array}$ & $\begin{array}{r}0.091459^{* * * *} \\
(3.19)\end{array}$ \\
\hline Bear Harvest_Gun & $\begin{array}{c}-0.01642 * * \\
(-2.31)\end{array}$ & $\begin{array}{c}-0.02568^{*} \\
(-1.93)\end{array}$ & $\begin{array}{r}-0.0421^{* *} \\
(-2.12)\end{array}$ \\
\hline Illegal Kills & $\begin{array}{c}0.583155^{* * * *} \\
(2.72)\end{array}$ & $\begin{array}{c}0.405926 \\
(1.03)\end{array}$ & $\begin{array}{r}0.989081^{*} \\
(1.88) \\
\end{array}$ \\
\hline Marauders & $\begin{array}{c}0.058485^{*} \\
(1.81)\end{array}$ & $\begin{array}{c}0.048802 \\
(0.66)\end{array}$ & $\begin{array}{r}0.107287 \\
(1.24)\end{array}$ \\
\hline Total Daily VEH Miles (mill) & $\begin{array}{c}0.055148 \\
(0.34)\end{array}$ & $\begin{array}{c}0.48649^{*} \\
(1.64)\end{array}$ & $\begin{array}{r}0.541638 \\
(0.99)\end{array}$ \\
\hline Pop Density & $\begin{array}{c}0.039489 \\
(0.86)\end{array}$ & $\begin{array}{c}-0.05452 \\
(-0.59)\end{array}$ & $\begin{array}{r}-0.01504 \\
(0.13) \\
\end{array}$ \\
\hline Mast Production & $\begin{array}{c}0.039318 \\
(0.11)\end{array}$ & $\begin{array}{c}-0.57476 \\
(-1.24)\end{array}$ & $\begin{array}{r}-0.53544 \\
(-0.56)\end{array}$ \\
\hline Farm Emp & $\begin{array}{c}-0.00113 \\
(-0.19)\end{array}$ & $\begin{array}{c}-0.01565 \\
(-1.38)\end{array}$ & $\begin{array}{r}-0.01678 \\
(-0.79)\end{array}$ \\
\hline $\begin{aligned} \lambda= & 0.431354 \\
& (7.75)\end{aligned}$ & $\begin{array}{c}R^{2}=0.8661 \\
\operatorname{Corr}^{2}=0.3309\end{array}$ & & \\
\hline $\begin{array}{l}\text { tats are in parentheses below the coef } \\
=95 \%, * * *=99 \% \text { with } N=330, \mathrm{R}^{\wedge} 2=0.8\end{array}$ & $\begin{array}{l}\text { nce levels a } \\
=0.8639 \text {. }\end{array}$ & 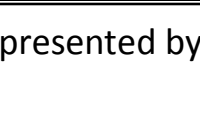 & $\%$ \\
\hline
\end{tabular}

To perform robustness checks, an SDEM from 2008-2013, using nuisance phone calls per 100 square miles in a county as the dependent variable, was conducted. These results are shown above in table 5 the first interesting result is that our spatial error correlation parameter is much more statistically significant than the previous model. Bears harvested using bow has a significant direct and total effect. Like the previous model, these results indicate that bow hunters are ineffective at eliminating bears.

Illegal kills had a positive direct and total effect. This seems to go against the original hypothesis that poachers are effective hunters. One theory for why this has a positive effect is that there are endogenity issues. For example, if an individual in rural West Virginia has called the DNR several times to report a marauding bear and the DNR do not come to assist, than that 
person may feel as though they have to kill the bear. ${ }^{57}$ Finally, marauding bears had a positive direct effect, which seems to agree with the previous model as well.

\subsection{Discussion}

This study was an attempt to determine if different hunting methods affect bear damage claims in different ways. Rather than grouping hunting together as one set activity, techniques were separated. The results suggest that hunting bears with a rifle is beneficial for a particular county but not necessarily so for surrounding counties. The opposite is true for bow hunting. Hunting bears with bows correlates with an increase in damage claims in the resident county and in surrounding counties. Additionally, harvesting bears with a bow corresponds to a net loss for the state. A bear harvested with a bow costs the state of West Virginia an average of about $\$ 77$. This is even after accounting for the revenue gained from the hunting license and the possible reduction of damages that bears could have caused.

This study marks the first time spatial econometric methods have been applied to the problems of bear management. This essay also agrees with the conclusion of the first essay that wildlife management policies do spillover. The externality of the policy is the impact it has on surrounding areas. Therefore, it is not enough to consider a single county when making management decisions. This result can be used to further inform wildlife management decisions because county wildlife decisions affect other counties.

A possible policy implication of this research concerns the use of alternative hunting methods. People hunt with a bow to "get back to their roots" or to "make it more sporting." The spirit of this idea can be addressed without sacrificing hunter effectiveness. West Virginia may want to consider adopting a more favorable view of hunting with crossbows. They are easier to use than a traditional bow and provide more lethality at a greater distance. A second option is to increase the number of muzzleloader black bear hunting opportunities. Hunting with a muzzleloader avoids the "stigma" of hunting with modern weapons while still maintaining a reasonable level of lethality and ease of use.

A suggestion of this research is that there are outside influences that can cause a bear to move. This movement many times crosses county lines. Note that the distance a bear has to

\footnotetext{
${ }^{57}$ Phone calls impacting illegal kills
} 
move does not have to be great in order to cross into a neighboring county. A farm located less than a tenth of a mile from the county border could have difficulties with bears from two separate counties. This does not suggest that all bears move into other counties. Bears located in the middle of a county do not spillover into neighboring counties in most circumstances (Maehr et al., 1988). However, the idea that bears do not move at all in response to outside stimulus is patently false. Therefore, bears that are located closer to the borders of a county may very well spillover into surrounding counties under the right circumstances. This is the bear movement represented in this analysis.

As big game management programs progress into the future, the need to understand the effects of hunting becomes more evident. Policy makers should be aware that not all hunting methods are the same and certainly do not impact game animals in the same way. There is a need to address revenue issues. Wildlife associated agencies and systems are heavily dependent on sportsmen for funding (Rott, 2018). Money generated from license fees and excise taxes on guns, ammunition, and angling equipment provide about $60 \%$ of the funding for state wildlife agencies, which manage most of the wildlife in the U.S (Rott, 2018). This system for wildlife conservation is lauded and emulated around the world. The system has restored the populations of North American game animals (Rott, 2018). However, with a slide in hunting participation expected to speed up in the next 10 years there is a growing sense of urgency in the wildlife conservation community to broaden that funding base (Rott, 2018). With different states adopting different management techniques, it may be time for West Virginia to revisit its bear management plan.

\subsection{Oceans of Fear: Introduction}

For most of us, a day at the beach is a chance to relax and enjoy the surf. Over the years, Americans were drawn to the sand and sea by the millions until a movie called Jaws made us wonder if it really was safe to go back in the water. Nevertheless, thousands of years before Hollywood, sharks were the subject of myths and legends. Mariners told tales of horrifying attacks on anglers and shipwrecked sailors. Some scholars even believe that the biblical story of Jonah and the Whale is based on an encounter with a great white shark (Ackroyd, 2017). Attacks have occurred all around the world including the southeastern and Gulf coasts of the United 
States and the coast of California as shown below in figure 7. Those who face an attack are in grave danger because sharks have an anatomy designed to kill.

\section{Figure 7: US Shark Attacks by County Since 2000 ${ }^{58}$}

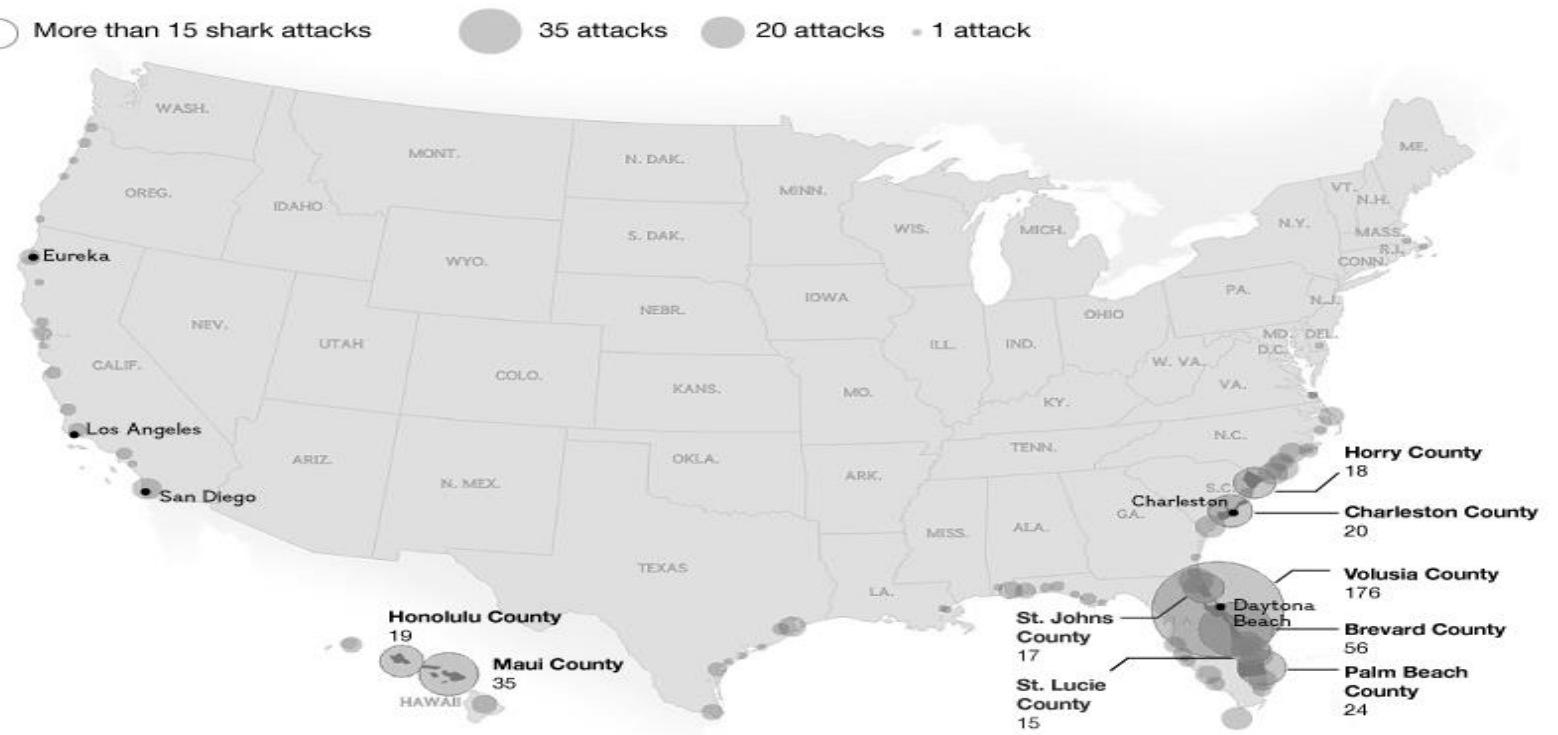

In spite of the shark's formidable weapons, attacks on humans are relatively rare and they are usually isolated incidents. A series of attacks by a single shark as in the movie Jaws is almost unheard of in documented cases (Ackroyd, 2017). Until the late 19th century, Americans frequently came to the shore to cool off but few ever ventured into the sea (Ackroyd, 2017). However, by the first decades of the 20th century, ocean swimming was becoming more popular and beaches were a fashionable place to spend the summer. At that time, the number of shark attacks began to rise as shown below in figure 8. In addition to the increased popularity of swimming, there are several other theories for why there has been an upward trend in shark attacks since 1930. Population was increasing at the time and automobiles were allowing more inland people to venture to the beach.

\footnotetext{
${ }^{58}$ Source: National Geographic "See Where Shark Attacks Happen in the United State
} 


\section{Figure 8: Trend of Unprovoked Shark Attacks ${ }^{59}$}

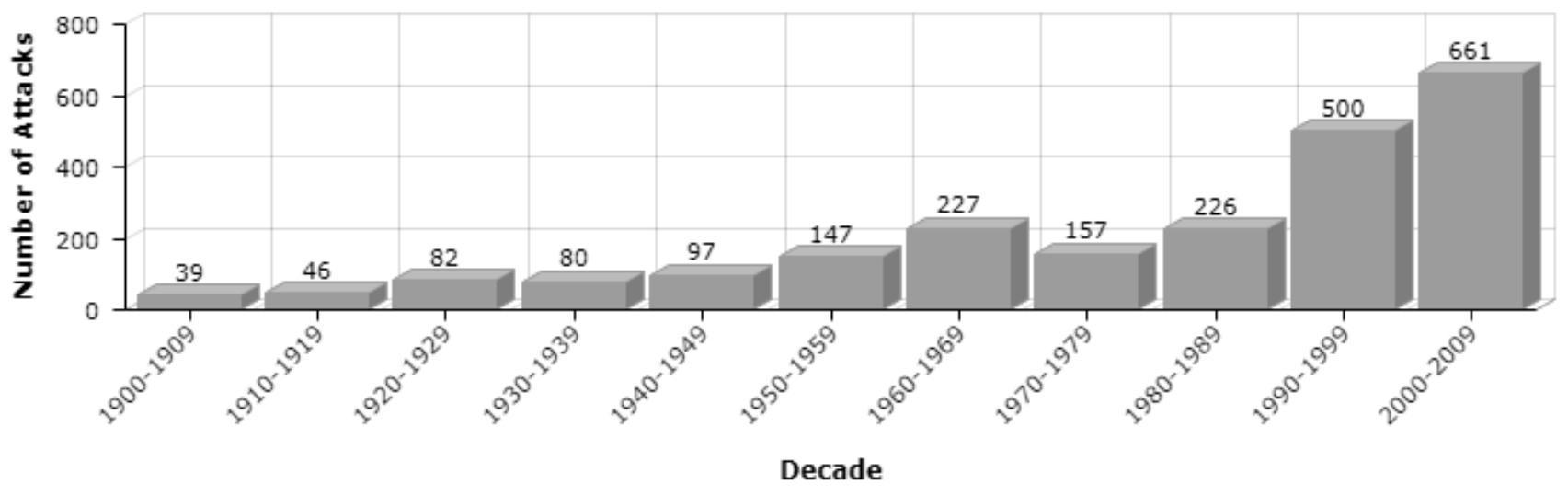

For the last 100 years, sharks have captivated popular culture. The Jersey Shore shark attacks of 1916 (5 attacks), the 2010 Sharm El Sheikh shark attacks (4 attacks), and the 2015 Outer Banks shark attacks ( 8 attacks) all received major public attention. Shark attacks are subject to sensationalism. Neff (2015) coined the term Jaws Effect. This is the idea that filmbased historical analogies are used as a political device to frame real-life events in ways that make the events governable push the agenda of particular policy agendas. Even the Discovery Channel's Shark Week has attracted much criticism for airing dramatic programs to increase viewers and popularity. In the same way that other forms of transportation experienced an increase in popularity after the September 11th terrorist attacks, people will seek alternatives to an activity they perceive as dangerous. Australia estimates that $\$ 2.86$ billion dollars in tourism revenue is lost due to reporting of fatal shark attacks (Pearl, 20170.

Considering sensationalized shark attacks have existed for an exceedingly long time, how does the public react to shark attacks? Using daily hotel occupancy data, this research is geared toward discovering how shark attacks impact beach goers. How does the public respond to shark attacks? How do shark attacks in coastal US counties impact hotel revenues? Is there a cyclical response to shark attacks?

\subsection{Literature Overview}

A famous line uttered from Mayor Larry Vaughn in Jaws was "You yell 'Barracuda,' everybody says 'Huh? What?' You yell 'Shark,' we've got a panic on our hands on the Fourth of July" and in some ways he was right. Few phrases in the world elicit as much fear as the words

\footnotetext{
${ }^{59}$ Source: International Shark Attack File
} 
"shark" and "attack." This fear goes as far back as the ancient civilizations of Greece and Rome (Peschak, 2014). There is also compelling evidence that sharks trailed slave ships across the Atlantic and feasted on human remains that were thrown overboard. This gruesome fact was used as an integral part of a system of terror by the slave ship captains (Peschak, 2014). It is agreed that the status of knowledge of the behavior range of most species is alarmingly incomplete (Bres, 1993). While sharks are clearly not mindless eating machines, they are apex predators in their environment and thus have little fear of any creature with which they cross paths (Burges, 2012). In fact, attacks boil down to an odds game based on how many hours you are in the water (BBC, 2001).

Despite the exceedingly low probability of shark attacks, people still are subject to the effects of fear, paralyzing efforts to think clearly about shark attacks (Sustein \& Zeckhauser, 2011). This was the case in Florida when a shark attack caused public dismay and discussion of new policies to control the predators (Sustein \& Zeckhauser, 2011). In this case, public anxieties were not resistant to the fact that the underlying risk was minuscule. Sometimes the emotional response to threats of shark attacks greatly exceeds the actual statistical risk. Even though most people agree that humans are not the typical diet of a typical shark, like most sophisticated hunters, they are curious when they encounter something unusual in their territories (Neff \& Hueter, 2013). Lacking any limbs with sensitive digits such as hands or feet, the only way they can explore an object or organism is to bite it; these bites are exploratory bites and can be extraordinarily devastating to human beings (Rice, 2011).

Neff (2015) was one of the first people to suggest a Jaws effect. He examined the use of film narratives by politicians to gain influence following well-publicized shark attacks. His three elements of the Jaws effect include the intention of the shark, perception that these events are fatal, and the belief that 'the shark' must be killed (Neff, 2015). Perhaps even more concerning to local officials was a study by Achen and Bartels (2004) that found voters punish governments for acts of God, including shark attacks. As long as responsibility for the event itself can be attributed to the government, the voters will take out their frustrations on the current administration.

There is some evidence that attack reporting is questionable. The perception that shark attacks are deliberate, malicious attempts to kill humans is outdated and misleading (Neff \& 
Hueter, 2013). Even shark week may be swaying public opinion in the "wrong" way. Myrick and Evans (2014) found that shark-on-human violence and presence of a public service announcement (PSA) influence fear reactions and perceived threat of shark attacks. Even the ominous background music in shark documentaries may be influencing the population's attitudes toward sharks (Nosal et al., 2016).

At the same time, there is evidence of potential economic benefits of having sharks nearby. Shark diving tourism is a burgeoning, global industry. The growing perception that sharks can be worth more alive for tourism than dead in a fish market has become one of the leading contemporary arguments for shark conservation (Gallagher et al., 2015) Dicken and Hosking (2009) highlighted the new tiger shark diving industry. However, it is difficult to place monetary values on environmental goods and services (King, 1995).

Finally, this research relates to disaster literature. The nature of these destructive events - as well as their effect on the economy — varies considerably. Some natural disasters, such as tornadoes, hurricanes and earthquakes, tend to be short-lived events. While only lasting several seconds to a few hours they cause substantial destruction in a concentrated area (Kliesen, 1994). Other longer duration disasters (like earthquakes or floods) can spread their damaging effects over a relatively large area for longer periods of time (Kliesen, 1994). Any disaster, however, can leave an economic crater that festers for years. Similar to BP's Deepwater Horizon disaster shark attacks are subject to misinformation by media outlets (Smith et al., 2010). Government support of local final demand can reduce the indirect losses associated with disasters. Oosterhaven and Többen (2017) modeled the attempts of economic actors to continue their usual activities, as closely as possible, by minimizing the information gain between the preand post-disaster pattern of economic transactions of the economy at hand. Findings show that government support of local final demand substantially reduces the indirect losses of the floods.

\subsection{Data and Methodology}

To measure people's reaction to shark attacks we use daily coastal hotel occupancy from 2005 to 2016 (is this correct) as our dependent variable. ${ }^{60}$ These are in terms of rooms currently rented at the hotel. We assume that since shark attacks are such publicized events people react strongly to these occurrences even if they are rare. The data are available at the daily level for

\footnotetext{
${ }^{60}$ Dr. Frank Stephenson in the Economics Department of Berry College, Georgia, provided these data.
} 
several North and South Carolina coastal counties (Carteret, Dare, New Hanover, Onslow, Beaufort in North Carolina and Charleston, Georgetown, and Horry in South Carolina). ${ }^{61}$ Unsurprisingly, the highest days of occupancy for coastal hotels were on Friday and Saturday. This is shown in figure 9. In addition, Horry County in South Carolina had the highest total occupancy for the period. Figure 10 shows that coastal hotel occupancy for these counties remained relatively stable for the 2005-2016 period. $^{62}$

Figure 9: Hotel Occupancy in Select Coastal Carolina Counties (2005 - 2016)

Hotel Occupancy (by area) 2005 -

2016

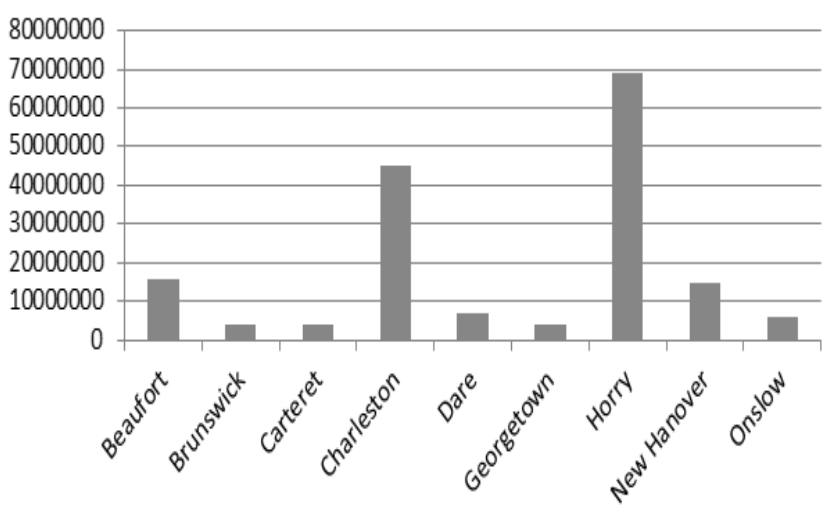

Hotel Occupancy (by day of week) 2005 - 2016

Figure 10: Total Hotel Occupancy in All Included Coastal Carolina Counties (2005 - 2016)

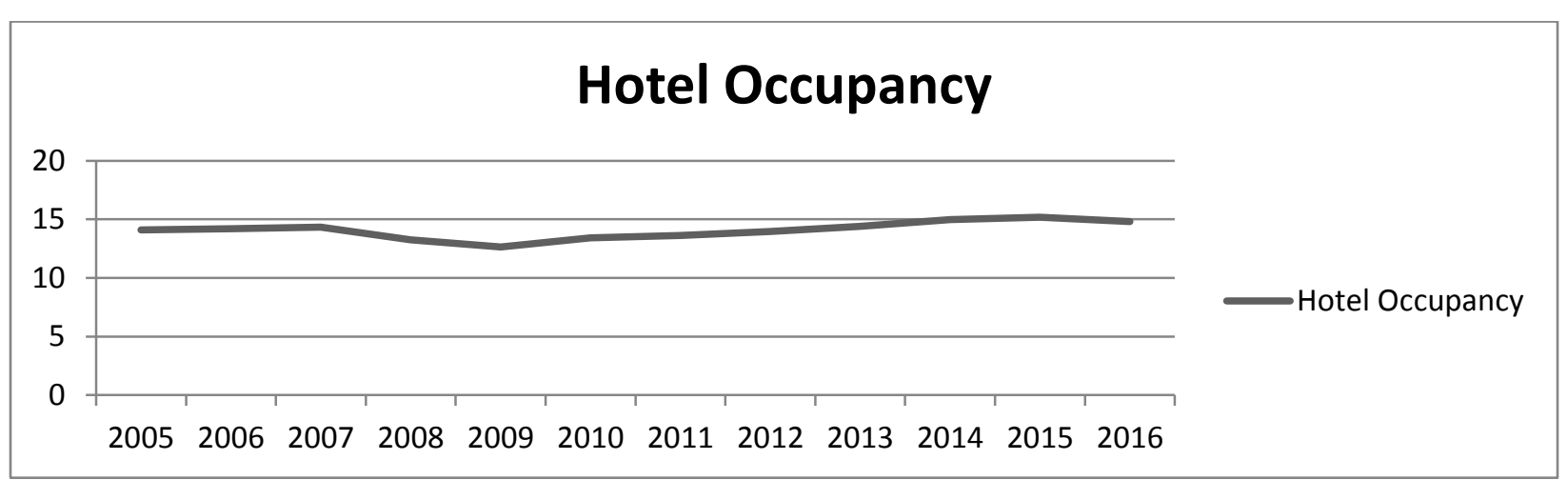

Shark attack data are available through the Global Shark Attack File. It provides details about shark attacks all over the world. Shark attacks are sorted by the coast of the county where

\footnotetext{
${ }^{61}$ Horry County is where Myrtle Beach is located and is one of the most common places to experience a shark attack in the US. Although we had anticipated including Colleton and Jasper Counties in SC, they are not included here because they have no coastal hotels.

${ }^{62}$ Due to reporting issues, the entirety of 2004 was dropped from this analysis.
} 
they occurred. There were 49 shark attacks during the 2005-2016 period in the counties in our analysis. The majority of attacks (12) occurred on Wednesdays and Horry County, South Carolina, had the most shark attacks with 16, as shown in figure 11. Figure 12 shows that there has been an upward trend in shark attacks over the 2005-2016 period. The worst year so far was 2015 when there were eight total shark attacks. ${ }^{63}$

Figure 11: Shark Attacks in Select Coastal Carolina Counties (2005 - 2016)

Shark Attacks (by area) 2005 - 2016

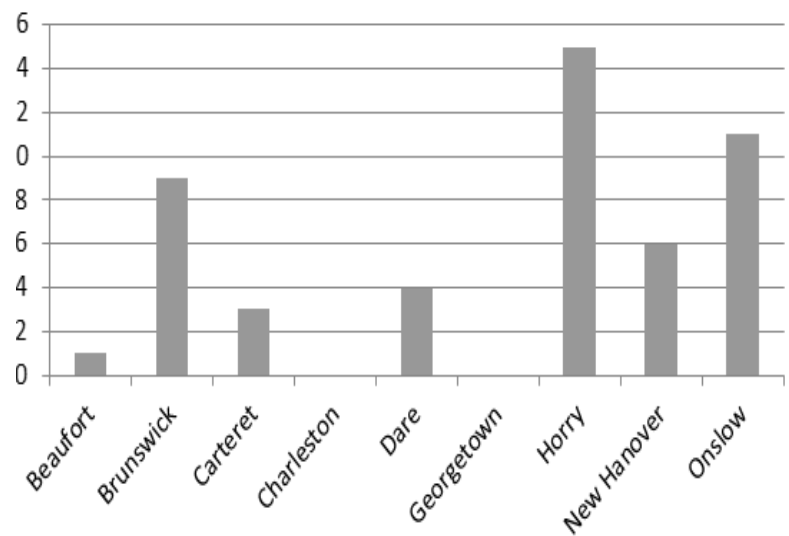

Shark Attacks (by day of week) 2005 2016

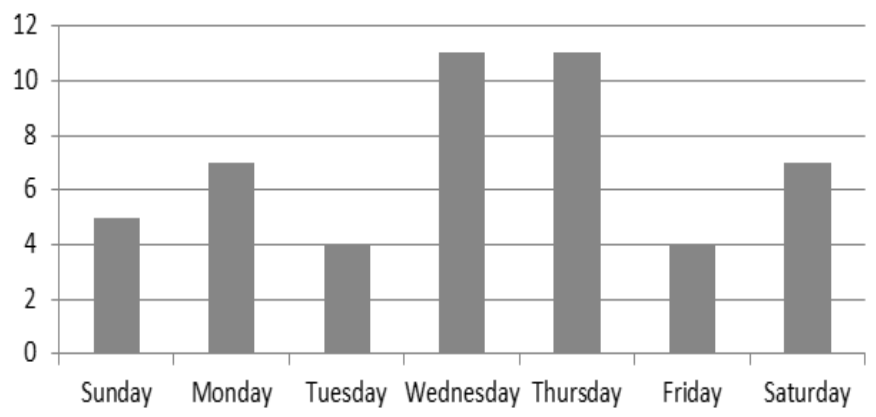

Figure 12: Total Shark Attacks in Included Coastal Carolina Counties (2005 - 2016)

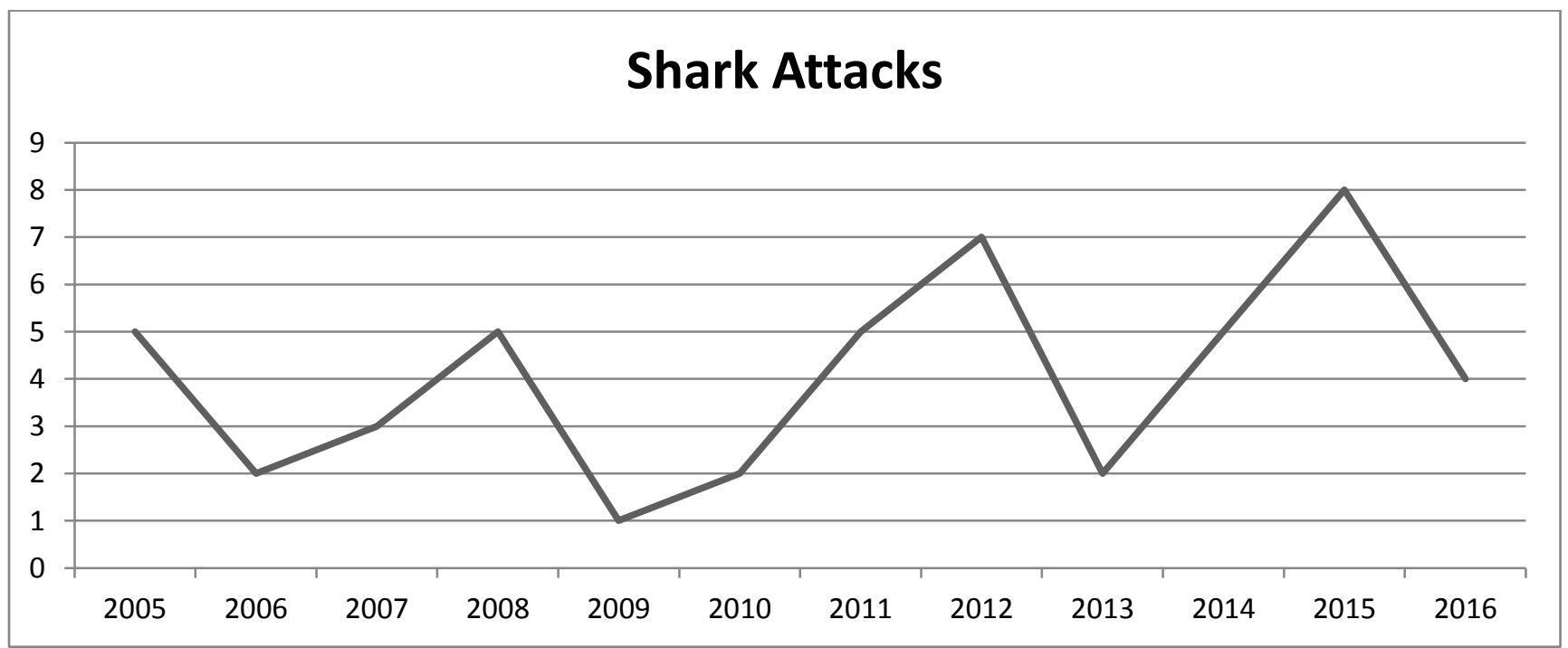

\footnotetext{
${ }^{63}$ According to the International Shark Attack File, the main drivers for the rise in incidents were warm water from an irregularly occurring and complex series of climatic changes (called El Niño) and global warming (2015 was one of the hottest year on record), a lack of severe storms in most developed countries, and a relatively strong economy that sent more vacationers to the beach.
} 
Endogenity issues may be associated with the variables. Burgess (2012) stated that as more and more people enter the water their chances of getting bitten increases. However, this can be accounted for by lagging the key variable ${ }^{64}$. We include lags of shark attacks of three days, one week, and a month. The lag of three days is because that is the amount of time you must cancel before for most of the coastal hotels to give you a refund. The one-week lag is to account for how long the average shark attack story is covered (Neff, 2015). Finally, the 30-day lag seems to be enough time for an individual or family to alter their trip. Given the hotels in our sample, shark attacks are treated as a dummy variable with a one if there was an attack that day and a zero otherwise. ${ }^{65}$

To account for other factors that may influence hotel occupants we include a dummy variable for weather severity. These were available through NOAA and included riptides, hurricanes, heavy rain, and waterspouts. A dummy variable was created for severe weather events (a one if there was a severe weather event that day, 0 otherwise). This should have a negative effect on hotel occupancy. Music festivals draw in large crowds at summer beaches. These crowds then often stay in hotels by the beach. They are included as a dummy variable ${ }^{66}$. Finally, we include the mean daily temperature in Fahrenheit at the county level. Generally, people want to go to the beach when it is warm outside and avoid the beach when it is cold outside. Descriptive statistics for the included variables are shown in table 6.

Table 6: Summary Statistics (Shark)

\begin{tabular}{|c|c|c|c|c|c|}
\hline Variable & Mean & $\begin{array}{c}\text { Standard } \\
\text { Deviation }\end{array}$ & Minimum & Maximum & Count \\
\hline Hotel Occupancy & 4313.39 & 5532.02 & 153 & 31422 & 39168 \\
\hline Weather Events & 0.008 & 0.092 & 0 & 1 & 39168 \\
\hline Mean Temp & 63.7 & 14.7 & 17 & 91.4 & 39168 \\
\hline Music Festival & 0.047 & 0.054 & 0 & 1 & 39168 \\
\hline Shark Attacks dummy 3dayLag & 0.001 & 0.033 & 0 & 1 & 39168 \\
\hline $\begin{array}{c}\text { Shark Attacks dummy 14day } \\
\text { lag }\end{array}$ & 0.001 & 0.033 & 0 & 1 & 39168 \\
\hline $\begin{array}{c}\text { Shark Attacks dummy 30day } \\
\text { lag }\end{array}$ & 0.001 & 0.033 & 0 & 1 & 39168 \\
\hline
\end{tabular}

\footnotetext{
${ }^{64}$ While shark attacks a week ago may affect hotel occupancy today, hotel occupancy today does not affect shark attacks a week ago.

${ }^{65}$ In our entire sample of 39,168 , there were only two days when more than one shark attack occurred. In one case, there were two and in the other, there were 3.

${ }^{66}$ This was done with a scraping program that looked for music festival flyers and advertisements.
} 


\subsection{Results}

The results of an SDEM spatial panel model are shown below in Table 7. We used a nearest neighbor weight matrix with only the closest county based on county centroids counting as a neighbor ${ }^{67}$ and a pooled model with spatial error autocorrelation, spatial and time period fixed effects. As stated in paper $2, \lambda$ is the spatial autocorrelation parameter and indicates that there is spatial error correlation that needs to be accounted for in the econometric model because it is positive and highly statistically significant. The weight matrix used in this study is a nearest neighbor matrix and uses centroids for the closest city to a coast in the county. $R^{2}$ and $\operatorname{Corr}^{2}$ indicate that the fixed effects in our model explain $92 \%$ of the variation in the dependent variable.

Table 7: Results SDEM Hotel Occupancy in Coastal Carolina Counties (2005 - 2015)

\begin{tabular}{|c|c|c|c|}
\hline Variable & Direct Effect & Indirect Effect & Total Effect \\
\hline Weather Events & $\begin{array}{l}-154^{*} \\
(-1.73)\end{array}$ & $\begin{array}{l}-151 * \\
(-1.77)\end{array}$ & $\begin{array}{l}-331 * \\
(-1.95)\end{array}$ \\
\hline Mean Temp & $\begin{array}{l}5.87 * * * \\
(4.54)\end{array}$ & $\begin{array}{c}0.106 \\
(0.106)\end{array}$ & $\begin{array}{c}5.98 * \\
(2.323)\end{array}$ \\
\hline Music Festival & $\begin{array}{c}57 \\
(1.45)\end{array}$ & $\begin{array}{c}-78 * \\
(-1.79)\end{array}$ & $\begin{array}{c}129 \\
(-0.25)\end{array}$ \\
\hline SharkAttacksdummy3dayLag & $\begin{array}{l}424 * \\
(1.83)\end{array}$ & $\begin{array}{l}-550 * * * \\
(-2.41)\end{array}$ & $\begin{array}{l}-152 \\
(1.61)\end{array}$ \\
\hline SharkAttacksdummy7daylag & $\begin{array}{c}-179 \\
(-0.78)\end{array}$ & $\begin{array}{c}88 \\
(0.38) \\
\end{array}$ & $\begin{array}{c}-56 \\
(-0.45) \\
\end{array}$ \\
\hline SharkAttacksdummy30daylag & $\begin{array}{l}-415^{*} \\
(-1.83)\end{array}$ & $\begin{array}{c}-204 \\
(-0.89)\end{array}$ & $\begin{array}{c}-612 \\
(-1.36)\end{array}$ \\
\hline $\begin{array}{c}\lambda=0.06 \\
(19.1) * * *\end{array}$ & $\begin{array}{c}R^{2}=0.9419 \\
\operatorname{Corr}^{2}=0.0213\end{array}$ & & \\
\hline \multicolumn{4}{|c|}{$\begin{array}{l}\text { T-stats are in parentheses below the coefficients. Significance levels are represented by } *=90 \% \text {, } \\
* *=95 \%, * * *=99 \% \text { with } N=39,168, \mathrm{R}^{\wedge} 2=0.9419 \text { and } \mathrm{R}^{\wedge} 2 \text { adj }=0.9418 .\end{array}$} \\
\hline
\end{tabular}

First, let us examine the direct effects. These indicate how a change in an explanatory variable in the county affects the dependent variable in that county. There are four statistically significant direct effects. Weather events, shark attacks with a three-day lag, mean daily

\footnotetext{
${ }^{67}$ A possible consideration would be to create a weight matrix where ALL other counties are neighbors. Even this strategy does not account for the choice to stay home or out of the water.
} 
temperature, and shark attack with a 30-day lag. Weather events have a negative direct effect. This means that severe weather events are correlated with a reduction in coastal hotel occupancy by 148 rooms.

The three-day lagged shark attack dummy was positive and statistically significant. This means that a shark attack in a coastal county three days ago is correlated with an increase in hotel occupancy by 423 . While this may seem odd at first, considering how many reporters flock to the beaches when shark attacks happen and that there are other activities that people can engage in on the beach it becomes less surprising.

The 30-day lagged shark attack is negative and has a direct effect of -415 . This means that if a shark attack occurred 30 days ago there will be 415 fewer room rentals now. This makes intuitive sense. After potentially hearing about the shark, attack for a month a family may decide to change plans. Perhaps go to the beach in a different county or not at all. Much of the spillovers could be to other, non-coastal counties.

The mean daily temperature (unlagged) has a positive direct effect of 5.87. This means an increase in the mean daily temperature of one degree is correlated with 5.87 additional occupied hotel rooms. People want to go to the beach when it is warm outside and avoid it when it is cold.

The indirect effects measure how a change in an independent variable in a county affects the dependent variable in neighboring counties. There are three statistically significant indirect effects: weather events, music festivals, and the 3-day lagged shark attack dummy. Weather events have a negative effect of 152. This means that if there is a severe weather event in a county, it will not only decrease hotel occupancy in your own county but decrease hotel occupancy in surrounding counties.

Musical festivals draw in individuals to an area. Its negative indirect effect indicates that individuals are coming to the county with the music festival instead of to other neighboring areas. When there is a music festival in a county, there is a correlated reduction of hotel occupancy in surrounding counties by 78 rooms.

Lastly, the indirect effect for the 3-day lagged shark attack is -550 . This indicates that if a shark attack occurred three days ago in your county there is a correlated decrease of 550 rooms in surrounding counties. This may be that people are avoiding all beaches due to the attacks, but 
the affected county is temporarily benefiting due to people are coming into that county to watch the spectacle.

The total effect is the sum of the direct and indirect effects. The SDEM allows direct and indirect effects to have opposite signs and their total effect is often insignificant. There are two statistically significant total effects here: weather events and mean daily temperature; weather events are associated with a decrease the total number of occupied hotel rooms while warmer weather appears to increase occupancy.

To put these results in perspective the average hotel room in a coastal Carolina county is about \$166 per night. A shark attack 30 days ago is associated with a decrease in hotel occupancy today of 415 (direct effect only, no spillovers). Assuming these were just one night visits that were canceled means that shark attacks 30 days ago cost the hotel approximately $\$ 68,890$ now. Considering the average daily hotel occupancy over this period was 4313 , a decrease of 415 occupants is almost $10 \%$ of the average hotel occupancy $(0.096) .{ }^{68}$

\subsection{Discussion}

This analysis has shown that the public reacts to shark attacks in an interesting way. According to the results, there is actually an increase in hotel occupancy 3 days after the attack, perhaps due to people are coming into the county to watch the spectacle. Given the media fascination with shark attacks, it is probably not surprising that this is the case. Perhaps most telling is a quote from Estelle Meyer an eyewitness of the Jersey Shore shark attacks of 1916 "My parents decided that we would go down to see what was going on and we did but we were never allowed to go on the water unless we were with a parent an adult." (Ackroyd, 2017). This means that a shark attack may actually draw in a crowd of onlookers in the short run. However, after the excitement dies down, it appears these people leave and others are hesitant to come to the hotels.

After the spectacle has died down, our results suggest that people begin to cancel their trips and vacation plans. This costs a considerable amount to the hotel industry in the form of $\$ 68,890$ in lost revenue. Therefore, when the mayor in Jaws said he thought the shark would destroy his town's summer tourism, he was not exactly wrong.

\footnotetext{
${ }^{68}$ Data concerning average stays of a person at a hotel is being collect to extend these results.
} 
Potential policy implications from this line of research include the construction of barriers that prevent sharks from accessing beaches. These range from floating nets (which prevent some sharks from accessing the beach) to physical walls. Walls are very effective but only are feasible in areas with low wave height. The next step is to determine what different kinds of barriers off of coastal Carolina beaches would cost and if this cost is offset by the damages that are mitigated. ${ }^{69}$

\subsection{Dissertation Conclusion}

These essays demonstrate the usefulness of spatial econometrics for wildlife managers. With the diverse values of the population of the United States, wildlife managers across the country are finding it more difficult to establish wildlife policies that are either socially acceptable or politically sustainable (Manfredo et al., 2017). Since it is necessary for wildlife managers to augment their current methods, spatial econometrics can serve a valuable role in wildlife management. Spatial econometrics allows for a more complete estimate of the impacts of different wildlife management policies. This dissertation does not suggest that GPS and radio collar studies are obsolete. Indeed several of these studies are what produced the data that ran the models. What it does suggest is that spatial econometrics is a viable complement for radio and GPS collar studies. This is because it allows users to track the movement of wildlife based on their impact on their surroundings.

Wildlife managers will inevitably need to reevaluate the effectiveness of bow hunting. The first two essays demonstrate that bow hunters are associated with monetary losses to the state. This, combined with the decreased lethality inherent with archery equipment, cannot be ignored. Unless states believe that the intrinsic value associated with archery hunting outweighs the costs, new policies are warranted. Suggestions include increased cost of archery permits, reduced regulations regarding crossbow hunting, and increasing the number of muzzleloader permits issued. Increasing the cost of archery permits could offset the losses to the state. ${ }^{70}$ Crossbows are a more effective form of archery equipment because they fire with more power and accuracy than a typical bow. Previously, crossbow hunting was only available a few days per

\footnotetext{
${ }^{69}$ Another additional step is to factor in Holiday beach stays and weekly cycles of both high amounts of guests and low amounts of guests.

${ }^{70}$ Some states have begun to increase their hunting permit costs. This includes Pennsylvania, Maryland, and Ohio.
} 
year. Extending crossbow hunting to encompass the entire archery season would increase the effectiveness of bow hunters and thereby decrease the associated wildlife issues (such as deerrelated auto accidents and bear damages). Muzzle-loading guns are similar to the rifles that were used by the early pioneers in the United States. While they have been given several modern updates, they still evoke images of the early American woodsman. Muzzle-loading hunters could therefore be more efficient while still maintaining the sporting attitudes and traditions that are so popular in hunting circles.

Finally, the research concerning shark attacks addressed a peculiarity of human behavior. Humanity seems to have a morbid fascination with sharks and shark attacks. This is mostly likely why programs such as Shark Week are so popular. However, given the time to search for alternatives individuals will adjust their beach vacations to avoid areas where shark attacks occur. As was suggested in the movie Jaws, this has a negative effect on hotel revenue. More severe attacks may cause more severe reactions and this is the next step for this line of research.

The issues addressed in this dissertation are only a small selection of what wildlife economics has to offer. Clearly, a plausible next step is to introduce the larger wildlife management community to spatial econometrics and demonstrate the usefulness of this tool. It is important to start presenting these issues not only in academic conferences, but also to the organizations and agencies that actually craft the regulations and policies. Every state has its own unique wildlife issue. In Texas, the problem is with feral pigs. Florida on the other hand has invasive python snakes and alligator attacks. Maryland has an excessively large black bear population, while Pennsylvania has an excessively large deer population. Additionally, shark attacks are a concern all along the East coast of the United States. These essays have only scratched the surface of the myriad of interesting research questions that wildlife economics has to offer and as we progress these issues will become more apparent. For example, shark attacks are not the only type of animal attack in the United States. Bears and Alligators attack people every year. Alligator attacks may even be affecting housing prices in the state of Florida. Bear attacks on the other hand are seldom fatal though they can cause severe injuries. In times where the bear population is, exceeding its cultural carrying capacity there may be more interactions with people. This in turn increases the likelihood that an individual may provoke a bear to attack. 
A potential research question here is how the hunting season structure of a lottery permit system affects hunter effectiveness.

Other wildlife research topics include the ever-prominent topic of poaching. While poaching in the United States receives far less attention than elsewhere in the world it does cost states a significant amount. While it is nearly impossible to stop poaching all together, it could be useful to determine the factors that influence the likelihood of poaching. Perhaps increasing the number of game wardens in one state merely pushing the poachers into surrounding states rather than eliminate poaching. Another more general concern is the effectiveness of predator introduction in mitigating some types of wildlife damages. Predators like wolves are sometimes introduced to an area to thin prey numbers. However, it is nearly impossible to force predators to hunt the prey species with which you are particularly concerned. In addition, predators may simply drive prey species into neighboring areas, merely shifting the problem to a new location.

Wildlife management has certainly changed over the years. New technology, better data collection, and an increased knowledge of the workings of the natural world, humanity as a whole has certainly learned to deal with wildlife in a more sustainable manner. However, the knowledge and technology has opened up our eyes to many new problems associated with wildlife. Only 90 million people lived in the United States when Theodore Roosevelt was establishing the first national forests and wildlife refuges (Pratt, $\mathrm{C}$ ); now, at a population exceeding 300 million, what will happen to wildlife and its habitats over the next 100 years?

\subsection{References}

Achen, C. H., \& Bartels, L. M. (2012). Blind retrospection: Why Shark Attacks are Bad for Democracy. Center for the Study of Democratic Institutions, Vanderbilt University. Working Paper.

Ackroyd, D. (2017). Shark Attacks of 1916. Documentary. Histories Mysteries. https://www.youtube.com/watch?v=6_4ROpsT1Wc

Alejandro, C., Alfonso, D. (2010). Comparison of Geographic Distribution Models of WhiteTailed Deer Odocoileus Virginianus Subspecies in Mexico: Biological and Management Implications. Therya, 1 (1): 41-68. 
Allen, R. E., \& McCullough, D. R. (1976). Deer-Car Accidents in Southern Michigan. The Journal of Wildlife Management, 317-325.

Allstate. (2011). How Does Hitting a Deer Impact Your Insurance? Allstate Auto Insurance. Retrieved October 12, 2014 from https://www.allstate.com/tools-and-resources/carinsurance/handling-a-deer-accident.aspx

Anderson, C., \& Waheed, A. (2001). The Economics of Shark and Ray Watching in the Maldives. Shark News, 13(1).

Anselin, L. (1988). Lagrange Multiplier Test Diagnostics for Spatial Dependence and Spatial Heterogeneity. Geographical Analysis, 20(1), 1-17.

Anselin, L., \& Bera, A. K. (1998). Spatial Dependence in Linear Regression Models with an Introduction to Spatial Econometrics. Statistics Textbooks and Monographs, 155, 237-290.

Anderson, D. J. (1983). Optimal Foraging and the Traveling Salesman. Theoretical Population Biology, 24(2), 145-159.

Ballard, W. B., Lutz, D., Keegan, T. W., Carpenter, L. H., \& deVos Jr, J. C. (2001). DeerPredator Relationships: A Review of Recent North American Studies with Emphasis on Mule and Black-Tailed Deer. Wildlife Society Bulletin, 99-115.

Bartley, W. A., \& Cohen, M. A. (1998). The Effect of Concealed Weapons Laws: An Extreme Bound Analysis. Economic Inquiry, 36(2), 258-265.

Baruch-Mordo, S., Breck, S. W., Wilson, K. R., \& Theobald, D. M. (2008). Spatiotemporal Distribution of Black Bear-Human Conflicts in Colorado, USA. The Journal of Wildlife Management, 72(8), 1853-1862.

BBC (2001)"Shark Attacks at Record High". BBC News. 9 February 2001. Retrieved April 6, 2016 from http://news.bbc.co.uk/2/hi/americas/1161702.stm

Bertalan, C. \& Bertalan, D. (2015). An Introduction to Black Bears. Untamed Science. Retrieved February 4, 2015 from http://blackbearinfo.com/

Bissonette, J. A., Kassar, C. A., \& Cook, L. J. (2008). Assessment of Costs Associated with Deer-Vehicle Collisions: Human Death and Injury, Vehicle Damage, and Deer Loss. HumanWildlife Conflicts, 2(1), 17-27.

Börger, L., Franconi, N., De Michele, G., Gantz, A., Meschi, F., Manica, A., Lovari, S. \& Coulson, T.I.M., (2006). Effects of Sampling Regime on the Mean and Variance of Home Range Size Estimates. Journal of Animal Ecology, 75(6), 1393-1405.

Brandenburg, D. M. (1996). Effects of Roads on Behavior and Survival of Black Bears in Coastal North Carolina. The University of Tennessee Knoxville. Working Paper 
Bres, M. (1993). The Behaviour of Sharks. Reviews in Fish Biology and Fisheries, 3(2), 133159.

Boydston, G. A., \& Gore, H. G. (1987). Archery Wounding Loss in Texas. Texas Parks and Wildlife Department. Austin, Texas. 16pp.

Bunnell, F. L., \& Tait, D. E. N. (1985). Mortality Rates of North American Bears. Arctic, 316323.

Bulte, E. H., Van Kooten, G. C., \& Swanson, T. (2003). Economic Incentives and Wildlife Conservation. University of Victoria. Working paper.

Burgess, George H. "How, When, \& Where Sharks Attack". International Shark Attack File. Retrieved 26 June 2016 from https://www.floridamuseum.ufl.edu/shark-attacks/odds/howwhere-when/

Chardonnet, P., Clers, B. D., Fischer, J., Gerhold, R., Jori, F., \& Lamarque, F. (2002). The Value of Wildlife. Revue scientifique et technique-Office international des épizooties, 21(1), 15-52.

Clark, B. (2014). A Deer in the Headlights: Evaluating the Impact of Indiana's Earn-A-Buck Deer Hunting Policy Package on Deer-Vehicle Collisions. Thesis. Marquette University. Print.

Cliff, G., \& Dudley, S. F. (2011). Reducing the Environmental Impact of Shark-Control Programs: A Case Study from KwaZulu-Natal, South Africa. Marine and Freshwater Research, 62(6), 700-709.

Corey, D. (2006) History of Wildlife Management. Johnson State College. Retrieved April 11, 2015 from http://kanat.jsc.vsc.edu/student/coreyd/History.htm

Cowan, I. M. (1972). The Status and Conservation of Bears (Ursidae) of the World: 1970. Bears: Their Biology and Management, 343-367.

Cromer, J. (2002). History of Wildlife Management in West Virginia. West Virginia Department of Natural Resources. Retrieved November 29, 2014 from

https://www.wvdnr.gov/wildlife/magazine/Archive/08fall/Vol8No2historyWildlifeManagement. pdf

DeNicola, A. J., \& Williams, S. C. (2008). Sharpshooting Suburban White-Tailed Deer Reduces Deer-Vehicle Collisions. Human-Wildlife Interactions, 69.

Dicken, M. L., \& Hosking, S. G. (2009). Socio-Economic Aspects of the Tiger Shark Diving Industry within the Aliwal Shoal Marine Protected Area, South Africa. African Journal of Marine Science, 31(2), 227-232.

DNR, Maryland. (2015). Maryland Black Bear History and Management. Maryland Department of Natural Resources. Retrieved January 23, 2016 from http://dnr2.maryland.gov/huntersguide/Pages/BearHunt_HistoryManagement.aspx 
Drukker, D. M., Peng, H., Prucha, I. R., \& Raciborski, R. (2013). Creating and Managing Spatial-Weighting Matrices with the Spmat Command. Stata Journal, 13(2), 242-286.

Elhorst, J. P., \& Fréret, S. (2009). Evidence of Political Yardstick Competition in France Using a Two-Regime Spatial Durbin Model With Fixed Effects*. Journal of Regional Science, 49(5), 931-951

Elhorst, J. P. (2010). Applied Spatial Econometrics: Raising The Bar. Spatial Economic Analysis, 5(1), 9-28.

Elhorst, JP. (2010a). Spatial Panel Data Models. In: Fischer MM, Getis A (eds) Handbook of applied spatial analysis. Springer, Berlin

Elhorst, JP. (2010b). Matlab Software for Spatial Panels. Retrieved March 13, 2015 from http://www.regroningen.nl/elhorst/doc/Matlab-paper.pdf

Elhorst, J. P. (2014). Spatial Panel Data Models. Spatial Econometrics (pp. 37-93). Springer Berlin Heidelberg.

Gallagher, A. J., Vianna, G. M., Papastamatiou, Y. P., Macdonald, C., Guttridge, T. L., \& Hammerschlag, N. (2015). Biological Effects, Conservation Potential, and Research Priorities of Shark Diving Tourism. Biological Conservation, 184, 365-379.

Gladfelter, H. L., Kienzler, J. M., \& Koehler, K. J. (1983). Effects of Compound Bow Use on Deer Hunter Success and Crippling Rates in Iowa. Wildlife Society Bulletin (1973-2006), 11(1), 7-12.

Grau, G. A., \& Grau, B. L. (1980). Effects of Hunting on Hunter Effort and White-Tailed Deer Behavior. The Ohio Journal of Science. v80, n4. 0030-0950.

Grove, Jeff. (2014). Increased Complaints Concerning Animal Damage. Testimony on 9/22/14. Presented to Pennsylvania Game Commission Board of Commissioners. Retrieved December 9, 2014 from https://www.pfb.com/policy-pfb/pfb-testimonies-comments/943-increasedcomplaints-from-animal-damage-92214

Hamilton R,. J. (1978). Ecology of the Black Bear in Southeastern North Carolina. M .S. Thesis, University of Georgia Athens 214pp.

Hayes, J. (2017). Pennsylvania Ranks Low for Deer Hunting. Pittsburgh Post-Gazette. Retrieved May 6, 2018 from https://www.pressreader.com/usa/pittsburgh-postgazette/20171217/281947428204763

Hebblewhite, M., \& Haydon, D. T. (2010). Distinguishing Technology from Biology: A Critical Review of the Use of GPS Telemetry Data in Ecology. Philosophical Transactions of the Royal Society of London B: Biological Sciences, 365(1550), 2303-2312. 
Hellgren, E. C., Vaughan, M. R., \& Stauffer, F. (1991). Macrohabitat Use by Black Bears in a Southeastern Wetland. The Journal of Wildlife Management, 442-448.

Horsley, S. B., Stout, S. L., \& DeCalesta, D. S. (2003). White-Tailed Deer Impact on the Vegetation Dynamics of a Northern Hardwood Forest. Ecological Applications, 13(1), 98-118.

Horsley, S., \& Stout, S. (2004). The Forest Nobody Knows. USDA Forest Service. Forest Science Review Issue 1. Retrieved May 8, 2017 from https://www.fs.fed.us/ne/newtown_square/publications/FSreview/FSreview1_04.pdf

Hristienko, H., \& McDonald Jr, J. E. (2007). Going Into the 21st Century: A Perspective on Trends and Controversies in the Management of the American Black Bear. Ursus, 18(1), 72-88.

Huffman, M. (2015). What Will Hitting A Deer do to Your Insurance Rates? Consumer Affairs. Retrieved November 14, 2016 from https://www.consumeraffairs.com/news/what-will-hitting-adeer-do-to-your-insurance-rates-091815.html

Huijser, M. P., McGowen, P. T., Fuller, J., Hardy, A., \& Kociolek, A. (2007).Wildlife-Vehicle Collision Reduction Study: Report to Congress (No. FHWA-HRT-08-034).

Hurley, AK. (2017). The Deer in Your Yard Are Here to Stay. Citylab. Retrieved October 16, 2017 from https://www.citylab.com/environment/2017/08/the-deer-in-your-yard-are-here-tostay/535938/

Hutchins, M. (2012). What the Future Holds: Challenges For the Profession and TWS. The Wildlife Professional 6(3): 83-87

Hutchins, M. (2013). What Lies Ahead for the Future of the Wildlife Professional?. Interview by Jordan C. Schaul. National Geographic. July 12, 2013. Retrieved February 4, 2018 from https://blog.nationalgeographic.org/2013/07/12/what-lies-ahead-for-the-future-of-the-wildlifeprofessional/

Iverson, A. L., \& Iverson, L. R. (1999). Spatial and Temporal Trends of Deer Harvest and DeerVehicle Accidents in Ohio. The Ohio Journal of Science. v99, n4 (September, 1999), 84-94

Kaiser, M. K., Jonides, J., \& Alexander, J. (1986). Intuitive Reasoning About Abstract and Familiar Physics Problems. Memory \& Cognition, 14(4), 308-312.

Kalenkoski, C. M., \& Lacombe, D. J. (2013). Minimum Wages and Teen Employment: A Spatial Panel Approach. Papers in Regional Science, 92(2), 407-417.

Kalenkoski, C. M., \& Lacombe, D. J. (2015). Using Spatial Econometric Techniques to Analyze the Joint Employment Decisions of Spouses. Journal of Labor Research, 36(1), 67-77.

Kilpatrick, H. J., LaBonte, A. M., \& Seymour, J. T. (2002). A Shotgun-Archery Deer Hunt in a Residential Community: Evaluation of Hunt Strategies and Effectiveness. Wildlife Society Bulletin, 478-486. 
Kliesen, K. (1994). The Economics of Natural Disasters. Federal Reserve Bank of St. Louis. Retrieved January 14, 2017 from https://www.stlouisfed.org/publications/regionaleconomist/april-1994/the-economics-of-natural-disasters

Lacombe, D. J., Holloway, G. J., \& Shaughnessy, T. M. (2014). Bayesian Estimation of The Spatial Durbin Error Model With an Application to Voter Turnout in The 2004 Presidential Election. International Regional Science Review, 37(3), 298-327.

Lapinski, M. K., Neuberger, L., Gore, M. L., Muter, B. A., \& Van Der Heide, B. (2013). Shark Bytes: Message Sensation Value and Emotional Appeals in Shark Diving Websites. Journal of Risk Research, 16(6), 733-751.

Leban, F. A., Wisdom, M. J., Garton, E. O., Johnson, B. K., \& Kie, J. G. (2001). Effect of Sample Size on the Performance of Resource Selection Analyses. In Radio tracking and animal populations (pp. 291-307).

LeSage, JP., Pace, RK. (2009). Introduction to Spatial Econometrics. CRC Press, Boca Raton, FL

LeSage, J. P., \& Pace, R. K. (2010). Spatial Econometric Models. In Handbook of Applied Spatial Analysis (pp. 355-376). Springer Berlin Heidelberg.

LeSage, J. P., \& Pace, R. K. (2014). The Biggest Myth in Spatial Econometrics. Econometrics, 2(4), 217-249.

Lewis, J. S., Rachlow, J. L., Horne, J. S., Garton, E. O., Wakkinen, W. L., Hayden, J., \& Zager, P. (2011). Identifying Habitat Characteristics to Predict Highway Crossing Areas for Black Bears within a Human-Modified Landscape. Landscape and Urban Planning, 101(2), 99-107.

Lindberg M. S., Walker J. (2007). Satellite Telemetry in Avian Research and Management: Sample Size Considerations. Journal of Wildlife. Management. 71, 1002-1009.

(doi:10.2193/2005-696)

Lott, Jr, J. R., \& Mustard, D. B. (1997). Crime, Deterrence, and Right-To-Carry Concealed Handguns. The Journal of Legal Studies, 26(1), 1-68.

Lott Jr, J. R. (1998). Concealed-Handgun Debate. The Journal of Legal Studies, 27, 221.

Maehr, D. S., Layne, J. N., Land, E. D., McCown, J. W., \& Roof, J. (1988). Long Distance Movements of a Florida Black Bear. Florida Field Naturalist, 16(1), 1-6.

Manfredo, M. J., Teel, T. L., Sullivan, L., \& Dietsch, A. M. (2017). Values, Trust, and Cultural Backlash in Conservation Governance: The Case of Wildlife Management in the United States. Biological Conservation, 214, 303-311.

McDowell, R. D., And H. W. Pillsbury. 1959. Wildlife Damage to Crops in the United States. The Journal of Wildlife Management. 23:140-141. 
McIvor, D. E., \& Conover, M. R. (1994). Perceptions of Farmers and Non-Farmers Toward Management of Problem Wildlife. Wildlife Society Bulletin (1973-2006), 22(2), 212-219.

McLaughlin, C. \& Smith, H. (1990). Baiting Black Bears: Hunting Techniques and Management Issues. Eastern Workshop of Black Bear Researchers and Managers. Retrieved June 22, 2015 from https://www.bearbiology.com/fileadmin/tpl/Downloads/EBBW/10th_EBBW/30_mclaughlin_bai ting_black_bears.pdf

McMullin, S. (2004). Demographics of Retirement and Professional Development Needs of State Fisheries and Wildlife Agency Employees. Unpublished report for U.S. Fish and Wildlife Service's National Conservation Training Center and AFWA.

McShea, W. J., Stewart, C. M., Kearns, L. J., Liccioli, S., \& Kocka, D. (2008). Factors Affecting Autumn Deer-Vehicle Collisions in a Rural Virginia County. Human-Wildlife Interactions, 76.

Milinski, M., \& Heller, R. (1978). Influence of a Predator on the Optimal Foraging Behaviour of Sticklebacks (Gasterosteus aculeatus L.). Nature, 275(5681), 642-644.

Murray, D. L. (2006). On Improving Telemetry-Based Survival Estimation. Journal of Wildlife Management, 70(6), 1530-1543.

Myrick, J. G., \& Evans, S. D. (2014). Do PSAs Take a Bite Out of Shark Week? The Effects of Juxtaposing Environmental Messages with Violent Images of Shark Attacks. Science Communication, 36(5), 544-569.

Northeast Black Bear Technical Committee (NBBTC). (2012). An Evaluation of Black Bear Management Options. West Virginia Department of Natural Resources. Retrieved June 2, 2015 from http://www.wvdnr.gov/hunting/PDFFiles/BearMgmtOptions.pdf

Neff, C. (2015). The Jaws Effect: How Movie Narratives are Used to Influence Policy Responses to Shark Bites in Western Australia. Australian Journal of Political Science, 50(1), 114-127.

Neff, C., \& Hueter, R. (2013). Science, Policy, and the Public Discourse of Shark "Attack": A Proposal for Reclassifying Human-Shark Interactions. Journal of environmental studies and sciences, 3(1), 65-73.

Neuland, Dan. (2011). Black Bear Hunting in Maryland. The Frederick News-Post. Retrieved May 2, 2015 from http://www.fredericknewspost.com/archive/black-bear-hunting-inmaryland/article_9a3a9756-2b9d-50c6-a618-01d3fc9c1317.html

Nosal, A. P., Keenan, E. A., Hastings, P. A., \& Gneezy, A. (2016). The Effect of Background Music in Shark Documentaries on Viewers' Perceptions of Sharks. PloS one, 11(8), e0159279. 
Novak, J. M., Scribner, K. T., Dupont, W. D., \& Smith, M. H. (1991). Catch-Effort Estimation of White-Tailed Deer Population Size. The Journal of Wildlife Management, 31-38.

Olsen, L. 1991. Compensation: Giving a Break to Ranchers and Bears. West. Wildlands1 7:2529.

Ordiz, A., Støen, O. G., Sæbø, S., Kindberg, J., Delibes, M., \& Swenson, J. E. (2012). Do Bears Know they are Being Hunted? Biological Conservation, 152, 21-28.

Oosterhaven, J., \& Többen, J. (2017). Wider Economic Impacts of Heavy Flooding in Germany: a Non-Linear Programming Approach. Spatial Economic Analysis, 12(4), 404-428.

Pace, R. K., \& Zhu, S. (2012). Separable Spatial Modeling of Spillovers and Disturbances. Journal of Geographical Systems, 14(1), 75-90.

Pelton, M.R. 1982. Black Bear. Pages 504-514 in J.A. Chapman and G.A. Feldhamer, eds. Wild Mammals of North America: Biology, Management, and Economics. John Hopkins University Press. Baltimore and London.

Pearl, H. (2017). Spate of Australia Shark Attacks Could Take a Bite Out of Tourism. Reuters. Retrieved January 7, 2018 from https://www.reuters.com/article/us-australia-sharkattacktourism-idUSKBN15B0KJ

Peschak, T. P. (2014). Sharks and People: Exploring Our Relationship with the Most Feared Fish in the Sea. University of Chicago Press.

Pratt, C. (2018). Previous 100 Years. Wildlife 2060. Florida Fish and Wildlife Conservation Commission. Retrieved March 18, 2018 from myfwc.com/conservation/specialinitiatives/wildlife-2060/previous-100/

Puglisi, M.J., Lindzey, J.S., Bellis, E.D. (1974). Factors Associated with Highway Mortality of White-Tailed Deer. Journal of Wildlife Management 38(4), 799-807.

Pyke, G. H. (1981). Optimal Foraging in Hummingbirds: Rule of Movement Between Inflorescences. Animal Behaviour, 29(3), 889-896.

Reiffenberger, J. C. (1974). Range and Movements of West Virginia Black Bear During Summer and Autumn 1973. In Proc. East. Workshop Black Bear Management and Res (Vol. 2, pp. 139142).

Rice, Xan (2011). "Great White Shark Jumps from Sea into Research Boat". The Guardian. London: Guardian Media Group. Retrieved July 20, 2016 from https://www.theguardian.com/world/2011/jul/19/great-white-shark-jumps-boat

Rimbey, N. R., R. L. Gardner, \& P. E. Paterson. 1991. Wildlife Depredation Policy Development. Rangelands 1 3:272-275. 
Roesenberry, C. Fleegle, J. \& Wallingford, B. (2011). Monitoring Deer Populations in Pennsylvania. Pennsylvania Game Commission. Retrieved August 18, 2014 from http://www.pgc.pa.gov/Wildlife/WildlifeSpecies/WhitetailedDeer/Documents/PASAK_Documentation.pdf

Rott, N. (2018). Decline In Hunters Threatens How U.S. Pays For Conservation. NPR: All Things Considered. Retrieved April 22, 2018 from https://www.npr.org/2018/03/20/593001800/decline-in-hunters-threatens-how-u-s-pays-forconservation.

Ryan, C. (2007). What the DNR is Finding Out about West Virginia Black Bears. West Virginia Division of Natural Resources. Retrieved May 24, 2015 from https://www.wvdnr.gov/wildlife/magazine/Archive/07winter/Vol7No3wvBlackBear.pdf

Ryan, C. W., Edwards, J. W., \& Duda, M. D. (2009). West Virginia Residents' Attitudes and Opinions Toward American Black Bear Hunting. Ursus, 20(2), 131-142.

Ryan, C. W., Pack, J. C., Igo, W. K., \& Billings, A. (2007). Influence of Mast Production on Black Bear Non-Hunting Mortalities in West Virginia. Ursus, 18(1), 46-53.

Sands, J. P., DeMaso, S. J., Schnupp, M. J., \& Brennan, L. A. (Eds.). (2012). Wildlife Science: Connecting Research with Management. CRC Press.

Schmitz. (2013). Report Puts Cost of Car-Deer Crashes at $\$ 400$ million in Pennsylvania. Pittsburgh Post-Gazette. Retrieved February 13, 2014 from http://www.postgazette.com/news/transportation/2013/10/16/Report-puts-cost-of-car-deer-crashes-at-400million-in-Pennsylvania/stories/201310160120

Schneck, M. (2014). Deer Hunting Seasons in Pennsylvania 145-Years-Old: A Brief History of Deer Hunting Laws and Regulations in Pennsylvania. PA Sportsman. . Retrieved January 12, 2017 from http://blog.pennlive.com/pasportsman/2014/11/deer_hunting_seasons_in_pennsy.html

Schneck, M. (2016). Pennsylvania Hunters Lose Lead Time Over Non-Residents for Doe Licenses. PA Sportsman. Retrieved January 12, 2017 from http://www.pennlive.com/pasportsman/2016/04/pennsylvania_hunters_lose_lead.html

Schwabe, K. A., Schuhmann, P. W., Tonkovich, M. J., \& Wu, E. (2000). An Analysis of DeerVehicle Collisions: the Case of Ohio. USDA National Wildlife Research Center Symposia

Schwabe, K.A., Schuhmann, P.W., and Tonkovich, M. (2002). A Dynamic Exercise in Reducing Deer-Vehicle Collisions: Management through Vehicle Mitigation Techniques and Hunting. Journal of Agricultural and Resource Economics 27(1), 261-280

Seiler, A. (2005). Predicting Locations of Moose-Vehicle Collisions in Sweden. Journal of Applied Ecology. 42(2), 371-382 
Simpfendorfer, C. A., Heupel, M. R., White, W. T., \& Dulvy, N. K. (2011). The Importance of Research and Public Opinion to Conservation Management of Sharks and Rays: a Synthesis. Marine and Freshwater Research, 62(6), 518-527.

Snelson, F., Mulligan, T. and Williams, S. (1984). Food Habits, Occurrence, and Population Structure of the Bull Shark, Carcharhinus Leucas, in Florida Coastal Lagoons. Bulletin of Marine Science.

Stowell, L. R., \& Willging, R. C. (1991). Bear Damage to Agriculture in Wisconsin. In Fifth Eastern Wildlife Damage Control Conference (1991) (p. 44).

Sudharsan, K., Riley, S. J., \& Winterstein, S. R. (2006). Relationship of Autumn Hunting Season to the Frequency of Deer-Vehicle Collisions in Michigan. Journal of Wildlife Management, 70(4), 1161-1164

Sunstein, C. R., \& Zeckhauser, R. (2011). Overreaction to Fearsome Risks. Environmental and Resource Economics, 48(3), 435-449.

Unger, K. 2007. The Graying of the Green Generation. The Wildlife Professional 1(1): 18-22

U.S Fish \& Wildlife Service. (2011). National Survey of Fishing, Hunting, and WildlifeAssociated Recreation. Retrieved April 3, 2018 from https://www.census.gov/prod/2012pubs/fhw11-nat.pdf

van Dyke, Fred (2008). Conservation Biology: Foundations, Concepts, Applications, 2nd ed. Springer Verlag. p. 478. ISBN 978-1-4020-6890-4.

Van Eerden, M. R. 1990. The Solution of Goose Damage Problems in the Netherlands, with Special Reference to Compensation Schemes. Ibis 132:253-261.

Vaughan, M. R., Scanlon, P. F., Mersmann, S. E. P., \& Martin, D. D. (1989). Black Bear Damage in Virginia. In Fourth Eastern Wildlife Damage Control Conference, 1989 (p. 42).

Viton, P. A. (2010). Notes on Spatial Econometric Models. City and Regional Planning, 870(03), 9-10.

Wagner, K. K., Schmidt, R. H., \& Conover, M. R. (1997). Compensation Programs for Wildlife Damage in North America. Wildlife Society Bulletin, 312-319.

Weltz, K., Kock, A. A., Winker, H., Attwood, C., \& Sikweyiya, M. (2013). The Influence of Environmental Variables on the Presence of White Sharks, Carcharodon Carcharias at Two Popular Cape Town Bathing Beaches: A Generalized Additive Mixed Model. PloS one, 8(7), e68554. 


\subsection{Data Sources}

Bureau of Economic Analysis. Compensation per Employee CA05N, Local Area Employment CA25N. http://www.bea.gov/

Government of Manitoba. Range of the North American Black Bear. (2014-2016)

https://www.gov.mb.ca/conservation/wildlife/problem_wildlife/black_bear.html

International Shark Attack File. Maps \& Data. Date Accessed: 04/02/2016.

https://www.floridamuseum.ufl.edu/shark-attacks/maps/

Pennsylvania Game Commission. License and Permit Data. Personal communication 04/01/2015. http://www.portal.state.pa.us/portal/server.pt/community/hunting/11348

Pennsylvania Department of Transportation. Crash statistic database. Date Accessed: 07/22/2015. http://www.dot.state.pa.us/

State Farm Insurance. (2012). Its West Virginia Again. Date Accessed 01/08/2015 https://www.statefarm.com/about-us/newsroom/2012/10/23/deer-vehicle-confrontations/

U.S. Census Bureau. County Quick Facts. Date Accessed: 09/19/2015. http://www.census.gov/

U.S. Department of Transportation. Highway Statistics 2014. Federal Highway Administration.

West Virginia Department of Education. Proficient Levels. (2009-2013).

http://wveis.k12.wv.us/nclb/pub/

West Virginia Department of Natural Resources. Big Game Bulletin (2005-2013).

http://www.wvdnr.gov/

West Virginia Department of Natural Resources. Annual Mast Survey (2005-2013).

http://www.wvdnr.gov/

West Virginia Department of Transportation. West Virginia Highway Classification (20052013). http://www.transportation.wV.gov/Pages/default.aspx

\subsection{Codes}

Don Lacombe provides Matlab codes for Spatial Econometrics on his website. http://community.wvu.edu/ djlacombe/matlab.html 